\title{
Gas phase ion chemistry of an ion mobility spectrometry based explosive trace detector elucidated by tandem mass spectrometry
}

\author{
Joseph Kozole ${ }^{1,2}$, Lauren A. Levine ${ }^{3}$, Jill Tomlinson-Phillips ${ }^{2}$, and Jason R. Stairs ${ }^{4}$ \\ ${ }^{1}$ Present Address: DuPont Central Research and Development, Experimental Station, Wilmington, DE \\ ${ }^{2}$ ORISE Fellow at the U.S. Department of Homeland Security, Science \& Technology Directorate, \\ Transportation Security Laboratory \\ ${ }^{3}$ Kutztown University, Department of Physical Sciences, Kutztown, PA \\ ${ }^{4}$ U.S. Department of Homeland Security, Science \&Technology Directorate, Transportation Security \\ Laboratory, Atlantic City International Airport, NJ \\ corresponding author: jason.stairs@hq.dhs.gov
}

\begin{abstract}
The gas phase ion chemistry for an ion mobility spectrometer (IMS) based explosive detector has been elucidated using tandem mass spectrometry. The IMS system, which is operated with hexachloroethane and isobutyramide reagent gases and an ion shutter type gating scheme, is connected to the atmospheric pressure interface of a triple quadrupole mass spectrometer (MS/MS). Product ion masses, daughter ion masses, and reduced mobility values for a collection of nitro, nitrate, and peroxide explosives measured with the IMS/MS/MS instrument are reported. The mass and mobility data together with targeted isotopic labeling experiments and information about sample composition and reaction environment are leveraged to propose molecular formulas, structures, and ionization pathways for the various product ions. The major product ions are identified as [DNT-H] $]^{-}$for DNT, [TNT-H] for TNT, $[\mathrm{RDX}+\mathrm{Cl}]^{-}$and $\left[\mathrm{RDX}+\mathrm{NO}_{2}\right]^{-}$for $\mathrm{RDX},[\mathrm{HMX}+\mathrm{Cl}]^{-}$and $\left[\mathrm{HMX}+\mathrm{NO}_{2}\right]^{-}$for $\mathrm{HMX},\left[\mathrm{NO}_{3}\right]^{-}$for $\mathrm{EGDN},[\mathrm{NG}+\mathrm{Cl}]^{-}$ and $\left[\mathrm{NG}+\mathrm{NO}_{3}\right]^{-}$for $\mathrm{NG},[\mathrm{PETN}+\mathrm{Cl}]^{-}$and $\left[\mathrm{PETN}+\mathrm{NO}_{3}\right]^{-}$for PETN, $\left[\mathrm{HNO}_{3}+\mathrm{NO}_{3}\right]^{-}$for $\mathrm{NH}_{4} \mathrm{NO}_{3},\left[\mathrm{NO}_{2}\right]^{-}$for DMNB, [HMTD- $\left.\mathrm{NC}_{3} \mathrm{H}_{6} \mathrm{O}_{3}+\mathrm{H}+\mathrm{Cl}\right]^{-}$and $\left[\mathrm{HMTD}+\mathrm{H}-\mathrm{CH}_{2} \mathrm{O}-\mathrm{H}_{2} \mathrm{O}_{2}\right]^{+}$for $\mathrm{HMTD}$, and $\left[\left(\mathrm{CH}_{3}\right)_{3} \mathrm{CO}_{2}\right]^{+}$for TATP. In general, the product ions identified for the IMS system studied here are consistent with the product ions reported previously for an ion trap mobility spectrometer (ITMS) based explosive trace detector, which is operated with dichloromethane and ammonia reagent gases and an ion trap type gating scheme. Differences between the explosive trace detectors include the $[\mathrm{NG}+\mathrm{Cl}]^{-}$and $[\mathrm{PETN}+\mathrm{Cl}]^{-}$product ions being major ions in the IMS system compared to minor ions in the ITMS system as well as the major product ion for TATP being $\left[\left(\mathrm{CH}_{3}\right)_{3} \mathrm{CO}_{2}\right]^{+}$for the IMS system and $\left[\left(\mathrm{CH}_{3}\right)_{2} \mathrm{CNH}_{2}\right]^{+}$for the ITMS system.
\end{abstract}


Keywords: explosives trace detector (ETD), ion mobility spectrometry (IMS), tandem mass spectrometry (MS), gas phase ion chemistry

All opinions expressed in this paper are the author's and do not necessarily reflect the policies and view of the Department of Homeland Security, Transportation Security Laboratory, Department of Energy, or Oak Ridge Institute for Science and Education. References herein to any specific commercial products, processes, equipment, or services does not constitute or imply its endorsement, recommendation, or favoring by the United States Government or the Department of Homeland Security, or any of its employees or contractors.

\section{Introduction}

A recent research effort has focused on elucidating the gas phase ion chemistry inherent to ion mobility spectrometry based explosive trace detectors (ETDs) using mass spectrometry. [1-3] The underlying objective of the research has been to attain a fundamental understanding of the ambient pressure ionization pathways that govern the operating principles of the ETD equipment and to leverage that knowledge to advance the effectiveness of current and next generation systems. To date, the research effort has entailed interfacing two widely deployed ETDs, namely an ion trap mobility spectrometer (ITMS) manufactured by Morpho Detection Inc. and an ion mobility spectrometer (IMS) manufactured by Smiths Detection Inc., to triple quadrupole mass spectrometers (MS/MS).

While both the ITMS/MS/MS and IMS/MS/MS instruments have been demonstrated to accurately measure the mass-to-charge ratios $(\mathrm{m} / \mathrm{z})$, collision-induced dissociation pathways, and reduced mobility $\left(K_{0}\right)$ values for the ion species formed in the respective ETD systems, this data has only been reported for a comprehensive list of explosives using the ITMS/MS/MS instrument. Because ambient pressure ionization pathways are sensitive to any variation in reaction environment, including temperature, reagent gas composition, and ion gating strategy, it is erroneous to assume that data from the ITMS based instrument can be unconditionally extrapolated to the IMS based instrument. [4-11] For example, the ITMS based instrument implements dichloromethane and ammonia reagent gases in addition to an ion trap type gating scheme, whereas, the IMS based instrument implements hexachloroethane and isobutyramide reagent gases in addition to an ion shutter type gating scheme.

With the aim of directly and comprehensively characterizing the gas phase ion chemistry inherent to reaction environment in the IMS based ETD system, product ion masses, daughter ion masses, and 
reduced mobility values for a collection of nitro, nitrate, and peroxide containing explosives have been measured using the IMS/MS/MS instrument. This data along with proposed molecular formulas, structures, and ionization pathways for the various product ions are reported, with closing discussion focused on examining similarities and differences between the ITMS and IMS based instruments.

\section{Materials and Methods}

\section{A. Instrumentation}

All new data presented here was acquired using either an unmodified benchtop IMS based ETD (Model 400B Smiths Detection Inc.) or a IMS based ETD (Model 400B Smiths Detection Inc.) interfaced to a SCIEX API 2000 triple quadrupole mass spectrometer (see figure S1 and table S1 in supplemental material). [1, 12, 13] Electric field strengths, timings, pressures, temperatures, gas flows, reagent chemicals, and internal calibrants for both the negative and positive polarity operation of the IMS system are summarized in table 1 . The IMS system is composed of a thermal desorber attached to a stainless steel housing containing a reaction region with ${ }^{63} \mathrm{Ni} \beta$-radiation source, an electrostatic ion shutter gate, an ambient pressure counter-flow drift region, and a faraday plate detector. [1, 13] During the operation of the IMS system, the thermal desorber is maintained at a temperature of $205^{\circ} \mathrm{C}$. For negative ion detection, hexachloroethane is used as the reagent chemical, 4-nitrobenzonitrile is used as the internal calibrant, and the IMS housing temperature is maintained at $115^{\circ} \mathrm{C}$. For positive ion detection, isobutyramide is used as both the reagent chemical and internal standard while the IMS housing temperature is maintained at $225^{\circ} \mathrm{C}$. Thermocouples are placed at multiple locations on the IMS housing and regularly monitored to ensure uniform temperature across the drift region. House air purified with a purge gas generator (Parker Balston Model 75) is used as the carrier and drift gases for both negative and positive polarity operation. The purified air is measured to have a water content of 110 ppm and a carbon dioxide content of 50-100 ppm using a moisture and carbon dioxide sensor.

The method used to interface the IMS system to the API 2000 is described elsewhere. [1, 14, 15] Briefly, the faraday plate in the IMS system is replaced with a custom faraday plate which contains a centered hole for passing a portion of the ion beam into the mass spectrometer. The custom faraday plate along with the unmodified portion of the IMS system are positioned immediately before the orifice in the atmospheric pressure interface of the API 2000 using a custom interface flange.

The API 2000 is composed of a differentially pumped interface and a triple quadrupole mass analyzer. [12] The differentially pumped interface, namely the skimmer electrode, is altered to include ion gating 
capabilities as well as to permit the electric field strengths and pressures in the interface to be adjusted. Specifically, the alternations involved electrically isolating the skimmer from the chamber of the mass spectrometer such that the electrode can be biased relative to ground as well as changing the opening in the skimmer such that the hole size in the electrode can be either $400 \mu \mathrm{m}$ or $1100 \mu \mathrm{m}$. A $400 \mu \mathrm{m}$ skimmer opening is used when a pressure of 1 mtorr is desired in the second stage of the differentially pumped interface while a $1100 \mu \mathrm{m}$ skimmer opening is used when a pressure of $8 \mathrm{mtorr}$ is desired.

\section{B. Data Acquisition}

The benchtop IMS instrument can only be used to obtain mobility spectra whereas the IMS/MS/MS instrument can be used to obtain mobility spectra, mass and tandem mass spectra in the continuous ion flow mode, mass spectra in the selected mobility monitoring mode, and mass-selected mobility spectra (see table S2 in supplemental material). $[1,4,14,16,17]$ To acquire a mobility spectrum, the ion gate in the IMS system is pulsed open to pass a packet of ions into the drift region and the ion intensity at the faraday plate is registered relative to the drift time between the ion gate and the faraday plate. In the continuous ion flow mode, the ion gates in the IMS system and the API 2000 are continuously held in the open position while the mass analyzer is operated in the scan only or product ion scan mode to acquire mass or tandem mass spectra. The selected mobility monitoring mode is used to acquire mass spectra for the individual peaks in a mobility spectrum. In the selected mobility monitoring mode, the ion gate in the IMS system is pulsed open while the ion gate in the API 2000 is opened after a specified time delay. The time delay is selected to permit only the ions with a desired mobility range to pass into the API 2000. This mobility filtered population is analyzed by operating the mass analyzer in the scan only mode to obtain a mass spectrum. To acquire a mass-selected mobility spectrum, the ion gate in the IMS system is pulsed open while the ion gate in the API 2000 is held in the open position and the mass analyzer is operated to pass only the ions with a specified $\mathrm{m} / \mathrm{z}$ (i.e. the mass analyzer is operated in the single ion monitoring mode). The ion intensity at the electron multiplier in the API 2000 is registered relative to the drift time between the ion gate in the IMS system and the electron multiplier in the mass spectrometer to produce a mobility spectrum for the ions with the specified $\mathrm{m} / \mathrm{z}$ only.

The differentially pumped interface of the API 2000 is operated with lower voltage gradients (i.e. a voltage of $2 \mathrm{~V}$ between the skimmer and $\mathrm{Q} O\left(\mathrm{~V}_{\mathrm{s}-\mathrm{Q} O}\right)$ ) and higher pressures (i.e. a pressure of $8 \mathrm{mtorr}$ in the second stage of the differentially pumped interface $\left.\left(\mathrm{P}_{\mathrm{QO}}\right)\right)$ to acquire mass and tandem mass spectra in the continuous ion flow and selected mobility monitoring modes. Conversely, higher voltages (i.e. a 
$\mathrm{V}_{\mathrm{s}-\mathrm{Q} 0}$ of $25 \mathrm{~V}$ ) and lower pressures (i.e. a $\mathrm{P}_{\mathrm{Q} 0}$ of 1 mtorr) are used to acquire mass-selected mobility spectra. The former settings are ideal for higher sensitivity measurements while the latter settings are ideal for reducing distortion and broadening of the ion packet during transit of the interface. $[1,15,18$, 19]

\section{Reduced Mobility Calculation}

Reduced mobility $\left(\mathrm{K}_{0}\right)$ is calculated using the equation:

(1) $K_{0}=\left(t_{d}{ }^{\text {cal }} \cdot K_{0}{ }^{\mathrm{cal}}\right) / t_{d}$

where $t_{d}{ }^{\text {cal }}$ is the drift time of the internal calibrant, $\mathrm{K}_{0}{ }^{\text {cal }}$ is the reduced mobility of the internal calibrant, and $t_{d}$ is the drift time of the ion of interest. [20] The $K_{0}{ }^{\text {cal }}$ value is calculated to be $1.75 \mathrm{~cm}^{2} \mathrm{~V}^{-1} \mathrm{sec}^{-1}$ for the negative polarity calibrant 4-nitrobenzonitrile and $1.50 \mathrm{~cm}^{2} \mathrm{~V}^{-1} \mathrm{sec}^{-1}$ for the positive polarity calibrant isobutyramide using the equation:

(2) $\mathrm{K}_{0}^{\mathrm{cal}}=\left(\mathrm{L} /\left(\mathrm{E} \cdot \mathrm{t}_{\mathrm{d}}{ }^{\mathrm{cal}}\right)\right) \cdot(273 / \mathrm{T}) \cdot(\mathrm{P} / 760)$

where $L$ is the length in $\mathrm{cm}, \mathrm{E}$ is the electric field strength in volts, $\mathrm{T}$ is the temperature in Kelvin, and $\mathrm{P}$ is the pressure in torr for the drift region of the IMS instrument. [20] Standard deviation for the $\mathrm{K}_{0}$ measurement is $\pm 0.03 \mathrm{~cm}^{2} \mathrm{~V}^{-1} \mathrm{sec}^{-1}$.

\section{Sample Preparation}

Explosives samples studied include dinitrotoluene (DNT), trinitrotoluene (TNT), cyclo-1,3,5-trimethylene2,4,6-trinitramine (RDX), cyclo-1,3,5,7-tetramethylene-2,4,6,8-tetranitramine (HMX), ethylene glycol dinitrate (EGDN), nitroglycerine (NG), pentaerythritol tetranitrate (PETN), 2,3-dimethyl-2,3dinitrobutane (DMNB), ammonium nitrate $\left(\mathrm{NH}_{4} \mathrm{NO}_{3}\right)$, hexamethylene triperoxide diamine (HMTD), and triacetone triperoxide (TATP). Samples were prepared by depositing dissolved explosive solutions onto polytetrafluoroethylene (PTFE) filters (Smiths Detection Inc) and drying the aliquot under a flow of purified air. The DNT, TNT, RDX, and HMX solutions were prepared in 1:1 methanol:acetonitrile, the NG solution was prepared in 1:1 methanol:ethanol, the PETN solution was prepared in methanol, the $\mathrm{NH}_{4} \mathrm{NO}_{3}$ solution was prepared in water, the EGDN, HMTD, and DMNB solutions were prepared in acetonitrile, and the TATP solutions were prepared in hexane. In addition to solution deposited samples, dry crystal deposited samples for HMTD and TATP were also interrogated, yielding no discernable difference in response compared to the solution deposited samples at similar dose levels. Sample amounts were $100 \mathrm{ng}$ for DNT, TNT, RDX, HMX, EGDN, NG, PETN, and DMNB and 1000 ng for $\mathrm{NH}_{4} \mathrm{NO}_{3}$, HMTD, and TATP. A PTFE substrate was selected to reduce influence from chemical background. 
Substrates from other materials, such as muslin or nomex, may influence desorption and ion chemistry differently, however, the differences are outside the scope of this work.

\section{Results and Discussion}

To characterize the gas phase ion chemistry of the IMS based ETD, a series of mobility, mass, tandem mass, and mass-selected mobility spectra were collected for the explosives DNT, TNT, RDX, HMX, EGDN, NG, PETN, $\mathrm{NH}_{4} \mathrm{NO}_{3}, \mathrm{HMTD}$, and TATP as well as the explosive taggant DMNB using both the benchtop IMS instrument and the IMS/MS/MS instrument. Mass spectra for DNT, TNT, RDX, HMX, NG, and PETN obtained in the negative ion detection mode are displayed in figure 1, along with an accompanying background mass spectrum displayed in figure $\mathrm{S} 2$ in the supplemental material; mass spectra for HMTD and TATP obtained in both the negative and positive ion detection modes are displayed in figure S3 in the supplemental material; mass-selected mobility spectra for RDX and PETN obtained in the negative ion detection mode are displayed in figure 2; and mobility spectra for $\mathrm{NH}_{4} \mathrm{NO}_{3}, \mathrm{HMTD}$, and TATP, along with mass spectra for the individual peaks in the mobility spectra, are displayed in figure 3 . The spectra for $\mathrm{NH}_{4} \mathrm{NO}_{3}$ were obtained in the negative ion detection mode while the spectra for HMTD and TATP were obtained in the positive ion detection mode. The TATP sample used to obtain the spectra in negative mode was unpurified (i.e. the TATP sample was not thoroughly washed after synthesis). No response was observed for a purified TATP sample in the negative ion detection mode while the response for TATP in the positive ion detection mode was the same whether a purified or unpurified sample was analyzed.

A summary of the molecular formulas, ion masses, daughter ion masses, and $\mathrm{K}_{0}$ values for the product ions from the analysis of the various explosives is provided in table 2. Molecular formulas for the product ions were derived using the ion masses from the mass spectra, isotopic abundance and spacing from the mass spectra, and the daughter ion masses from the tandem mass spectra in combination with targeted isotopic labeling experiments and information about sample composition and reaction environment. The following discussion, which is assisted by experimental and computational findings from the literature, identifies the ion species formed during the above analyses as well as proposes ionization pathways for their formation in the IMS based ETD. Proposed molecular structures and ionization schemes are illustrated in figure 4 as well as figure $\$ 3$ in the supplemental material to aid the discussion.

\section{A. Reactant Ion Chemistry}


Reactant and product ion formation in the IMS based ETD is achieved by atmospheric pressure chemical ionization. $[13,21]$ The processes that govern ionization at atmospheric pressure are dependent on the chemical composition and temperature in the reaction environment. The reaction region in the IMS system is composed of purified air with parts per million ( $\mathrm{ppm})$ water and carbon dioxide in addition to high and low energy electrons from the $\mathrm{Ni}^{63}$ source and $\mathrm{H}^{+} \cdot \mathrm{xH}_{2} \mathrm{O}$ and $\mathrm{O}_{2}^{-} \cdot \mathrm{xH}_{2} \mathrm{O}$ cluster ions from the interaction of the electrons with nitrogen, oxygen, and water. [4, 22, 23] The temperatures for the thermal desorber, sample inlet, and reaction region in the IMS instrument are maintained above the decomposition temperatures for most of the explosives studied, introducing the possibility for thermal decomposition during sample analysis. [24-27]

For negative mode operation, hexachloroethane reagent chemical at the $10-50 \mathrm{ppm}$ level is introduced into the reaction region via the sample gas. The hexachloroethane reagent interacts with $\mathrm{O}_{2}^{-} \cdot \mathrm{xH}_{2} \mathrm{O}$ to yield $\mathrm{Cl}^{-} \cdot \mathrm{xH}_{2} \mathrm{O}$ and $\mathrm{Cl}_{2}^{-} \cdot \mathrm{xH}_{2} \mathrm{O}$ reactant ions in addition to chlorocarbon fragments (scheme I in figure 4). [4, 7] The $\mathrm{Cl}^{-} \cdot \mathrm{xH}_{2} \mathrm{O}$ and $\mathrm{Cl}_{2}^{-} \cdot \mathrm{xH}_{2} \mathrm{O}$ reactant ions, which will be denoted as $[\mathrm{Cl}]^{-}$and $\left[\mathrm{Cl}_{2}\right]^{-}$, serve as the main source for charge transfer to analyte molecules in the negative ion detection mode. For positive mode operation, isobutyramide (IBA) reagent chemical (which also serves as the internal calibrant) is introduced into the reaction region at the ppm level via the drift gas. The isobutyramide reagent interacts with $\mathrm{H}^{+} \cdot \mathrm{xH}_{2} \mathrm{O}$ to form primarily $2 \mathrm{IBA} \cdot \mathrm{H}^{+} \cdot \mathrm{xH}_{2} \mathrm{O}$ (scheme ii). The $2 \mathrm{IBA} \cdot \mathrm{H}^{+} \cdot \mathrm{xH}_{2} \mathrm{O}$ reactant ion, which will be denoted as $[2 \mathrm{IBA}+\mathrm{H}]^{+}$, serves as the main source for charge transfer to analyte molecules in the positive ion detection mode.

\section{B. Nitro-Organic Ion Chemistry}

The product ions for the nitrotoluene explosives DNT and TNT are deprotonated [DNT-H] ${ }^{-}$and [TNT-H]'. The [DNT-H $^{-}$and [TNT-H $^{-}$product ions are formed via a proton abstraction reaction between a nitrotoluene compound and a chloride reactant ion (schemes iii and iv). [7, 8, 28] Abstraction of a proton from a nitrotoluene is likely to occur at the methyl group due to the electronegative nitro groups and aromatic ring withdrawing electrons from the methyl group, causing the hydrogen atoms in the methyl group to exhibit acidic properties. [29] Because the proton affinity for $[\mathrm{Cl}]^{-}\left(\Delta_{\mathrm{f}} \mathrm{H}=-1394 \mathrm{~kJ} / \mathrm{mol}\right)$ and $\left[\mathrm{Cl}_{2}\right]^{-}\left(\Delta_{\mathrm{f}} \mathrm{H}=-1404 \mathrm{~kJ} / \mathrm{mol}\right)$ are roughly equal, it is possible that proton abstraction from a nitrotoluene may occur via $\left[\mathrm{Cl}^{-}\right.$or $\left[\mathrm{Cl}_{2}\right]^{-}$. $[7,30]$ Moreover, because the electron affinity is larger for $\mathrm{Cl}$ $\left(\Delta_{\mathrm{f}} \mathrm{H}=-332 \mathrm{~kJ} / \mathrm{mol}\right)$ than $\mathrm{Cl}_{2}\left(\Delta_{\mathrm{f}} \mathrm{H}=-241 \mathrm{~kJ} / \mathrm{mol}\right)$, the $\left[\mathrm{Cl}_{2}\right]^{-}$reactant ion may undergo decay to [Cl] $]^{-}$ before abstracting a proton (scheme iv). $[7,30,31]$ The $[D N T-H]^{-}$and $[$TNT-H] assignments are supported by the observation of the $[\mathrm{M}-\mathrm{H}-\mathrm{xNO}]^{-}$daughter ions in the respective tandem mass spectra, 
which are attributed to $\mathrm{C}-\mathrm{NO}_{2} \rightarrow \mathrm{C}-\mathrm{ONO}$ rearrangement followed by $\mathrm{N}-\mathrm{O}$ bond homolytic cleavage. [32] No other product ions were observed for either DNT or TNT, indicating that [DNT-H] ${ }^{-}$and $\left[\right.$TNT-H] ${ }^{-}$are characterized by excellent chemical and thermal stability.

Excluding proton abstraction from nitrotoluene, ion-molecule attachment and autoionization are the predominant ionization pathways for all other nitro-organic explosives. For the nitroamine explosives, the major (i.e. higher intensity) product ions are $[\mathrm{RDX}+\mathrm{Cl}]^{-}$and $\left[\mathrm{RDX}+\mathrm{NO}_{2}\right]^{-}$for $\mathrm{RDX}$ and $[\mathrm{HMX}+\mathrm{Cl}]^{-}$and $\left[\mathrm{HMX}+\mathrm{NO}_{2}\right]^{-}$for $\mathrm{HMX}$. The $[\mathrm{RDX}+\mathrm{Cl}]^{-}$and $[\mathrm{HMX}+\mathrm{Cl}]^{-}$product ions are formed via an ion-molecule attachment reaction between a $[\mathrm{Cl}]^{-}$reactant ion and a nitroamine compound. [21, 24, 33-35] A possible mechanism for the ion-molecule attachment event is an ion-dipole interaction between the reactant ion and a dipole in the nitroamine induced by the electron withdrawing nitro groups and the electrophilic hydrogen atoms being positioned on opposite sides of the equatorial plane of the amine ring (scheme v). [36] Non-covalent interaction between the $\left[\mathrm{Cl}^{-}\right.$reactant ion and nitroamine is supported by the strong response for $[\mathrm{Cl}]^{-}$in the tandem mass spectra for the $[\mathrm{RDX}+\mathrm{Cl}]^{-}$and $[\mathrm{HMX}+\mathrm{Cl}]^{-}$ adducts. The $\left[\mathrm{RDX}+\mathrm{NO}_{2}\right]^{-}$and $\left[\mathrm{HMX}+\mathrm{NO}_{2}\right]^{-}$product ions are formed via an autoionization reaction with a $\left[\mathrm{NO}_{2}\right]^{-}$fragment ion. $[24,25,33,37,38]$ The $\left[\mathrm{NO}_{2}\right]$ fragment is presumably generated by first-order thermal homolysis of a $\mathrm{N}-\mathrm{NO}_{2}$ bond in a nitramine compound during sample desorption (scheme vi). The pathway is substantiated by the favorable kinetics associated with $\mathrm{N}-\mathrm{NO}_{2}$ bond cleavage in addition to the $\mathrm{N}-\mathrm{NO}_{2}$ bond dissociation energy $\left(\mathrm{D}_{\mathrm{EN}-\mathrm{NO} 2}\right.$ in RDX $=163 \mathrm{~kJ} / \mathrm{mole}$ ) being smaller than any other bond in the compound ( $D_{E}$ other in $\mathrm{RDX} \geq 305 \mathrm{~kJ} / \mathrm{mole}$ ) and roughly equal to the activation energy for vaporization $\left(\mathrm{E}_{\mathrm{ARDX}}=131 \mathrm{~kJ} / \mathrm{mole}\right) .[25,39-41]$ Similar to $[\mathrm{RDX}+\mathrm{Cl}]^{-}$and $[\mathrm{HMX}+\mathrm{Cl}]^{-}$, the $\left[\mathrm{RDX}+\mathrm{NO}_{2}\right]^{-}$and $\left[\mathrm{HMX}+\mathrm{NO}_{2}\right]^{-}$ adducts are formed by ion-dipole interaction between a $\left[\mathrm{NO}_{2}\right]^{-}$fragment ion and nitroamine compound, which is supported by the strong response for $\left[\mathrm{NO}_{2}\right]^{-}$in the respective tandem mass spectra. The minor (i.e. lower intensity) product ions observed for RDX include $\left[\mathrm{RDX}-\mathrm{HNO}_{2}+\mathrm{Cl}\right]^{-},\left[\mathrm{RDX}+\mathrm{Cl}_{2}\right]^{-}$, and $[\mathrm{RDX}+\mathrm{Cl}+\mathrm{RDX}]^{-}$. Likewise, the minor product ions observed for $\mathrm{HMX}$ include $\left[\mathrm{HMX}-\mathrm{HNO}_{2}+\mathrm{Cl}\right]^{-},\left[\mathrm{HMX}+\mathrm{Cl}_{2}\right]^{-}$ , and $[\mathrm{HMX}+\mathrm{Cl}+\mathrm{HMX}]^{-}$. The $\left[\mathrm{RDX}-\mathrm{HNO}_{2}+\mathrm{Cl}\right]^{-}$and $\left[\mathrm{HMX}-\mathrm{HNO}_{2}+\mathrm{Cl}\right]^{-}$minor ions are formed via thermolysis of a ${\mathrm{N}-\mathrm{NO}_{2}}_{2}$ bond in a nitroamine compound followed by an ion molecule attachment reaction with $[\mathrm{Cl}]^{-}$, whereas, the $\left[\mathrm{RDX}+\mathrm{Cl}_{2}\right]^{-}$and $\left[\mathrm{HMX}+\mathrm{Cl}_{2}\right]^{-}$minor ions are formed via an ion-molecule attachment reaction between a $\left[\mathrm{Cl}_{2}\right]^{-}$reactant ion and a nitroamine compound (scheme vii). The $[\mathrm{RDX}+\mathrm{Cl}+\mathrm{RDX}]^{-}$and $[\mathrm{HMX}+\mathrm{Cl}+\mathrm{HMX}]^{-}$minor ions are generated by ion-dipole attachment of a $[\mathrm{Cl}]^{-}$reactant ion to a nitroamine compound followed by ion-dipole attachment of an additional nitroamine compound to form a nitroamine dimer complex bridged by [Cl] ${ }^{-}$(scheme viii). [34, 36] 
Similar ionization pathways for the nitroamine explosives are observed for the nitrate ester explosives. The major product ions for the nitrate ester explosives are $\left[\mathrm{NO}_{3}\right]^{-}$for $\mathrm{EGDN},[\mathrm{NG}+\mathrm{Cl}]^{-}$and $\left[\mathrm{NG}+\mathrm{NO}_{3}\right]^{-}$for $\mathrm{NG}$, and $[\mathrm{PETN}+\mathrm{Cl}]^{-}$and $\left[\mathrm{PETN}+\mathrm{NO}_{3}\right]^{-}$for PETN. The $[\mathrm{NG}+\mathrm{Cl}]^{-}$and $[\mathrm{PETN}+\mathrm{Cl}]^{-}$product ions are formed via an ion-molecule attachment reaction between a $[\mathrm{Cl}]^{-}$reactant ion and a nitrate ester compound driven by ion-dipole interaction. [21, 24, 33, 35] Favorable electrostatic interaction between the $[\mathrm{Cl}]^{-}$reactant ion and nitrate ester compound require axial reorientation of the electron withdrawing nitrate groups and electrophilic hydrogen atoms around the alpha carbons in the nitrate ester (scheme ix). [2] The $\left[\mathrm{NG}+\mathrm{NO}_{3}\right]^{-}$and $\left[\mathrm{PETN}+\mathrm{NO}_{3}\right]^{-}$product ions are formed via an autoionization reaction with a $\left[\mathrm{NO}_{3}\right]^{-}$ fragment ion (scheme $\mathrm{x}$ ). $[21,24,25,33,37]$ The $\mathrm{NO}_{3}$ fragment is likely generated from a nitrate ester compound by multi-order decomposition during sample desorption. Fragmentation of the nitrate esters is possibly initiated by thermal homolysis of a $\mathrm{CO}-\mathrm{NO}_{2}$ bond to yield a nitrate ester alkoxy radical and $\left[\mathrm{NO}_{2}\right]$ fragment, a pathway supported by the $\mathrm{CO}-\mathrm{NO}_{2}$ bond dissociation energy $\left(\mathrm{D}_{\mathrm{E}}\right.$ CO-NO2 PETN $=183$ $\mathrm{kJ} /$ mole) being smaller than any other bond in the compound ( $D_{E}$ other $\geq 332 \mathrm{~kJ} / \mathrm{mole}$ ) as well as the activation energy for vaporization $\left(E_{A \text { PETN }}=233 \mathrm{~kJ} / \mathrm{mole}\right)$. $[25,42-45]$ The pathway for formation of the $\mathrm{NO}_{3}$ fragment from the $\mathrm{NO}_{2}$ fragment may involve a bimolecular substitution reaction between the $\mathrm{NO}_{2}$ fragment and a nitrate ester compound in which a $\mathrm{C}-\mathrm{NO}_{2}$ bond is formed concurrent with $\mathrm{C}-\mathrm{ONO}_{2}$ cleavage to release $\mathrm{NO}_{3}$. [46] The minor product ions observed for $\mathrm{NG}$ include [NG-NO$+\mathrm{N}_{2}+\mathrm{HI}$ ], [NG$\left.\mathrm{NO}_{2}+\mathrm{H}+\mathrm{NO}_{3}\right]^{-}$, and $\left[\mathrm{NG}+\mathrm{Cl}_{2}\right]^{-}$, whereas, the minor product ions observed for PETN include [PETN$\left.\mathrm{NO}_{2}+\mathrm{H}+\mathrm{Cl}\right]^{-},\left[\mathrm{PETN}-\mathrm{NO}_{2}+\mathrm{H}+\mathrm{NO}_{3}\right]^{-}$, and $\left[\mathrm{PETN}+\mathrm{Cl}_{2}\right]^{-}$. No minor product ions were observed for EGDN. The $\left[\mathrm{NG}-\mathrm{NO}_{2}+\mathrm{H}+\mathrm{Cl}\right]^{-},\left[\mathrm{NG}-\mathrm{NO}_{2}+\mathrm{H}+\mathrm{NO}_{3}\right]^{-},\left[\mathrm{PETN}-\mathrm{NO}_{2}+\mathrm{H}+\mathrm{Cl}\right]^{-}$, and $\left[\mathrm{PETN}-\mathrm{NO}_{2}+\mathrm{H}+\mathrm{NO}_{3}\right]^{-}$minor ions are formed via thermolysis of a $\mathrm{C}-\mathrm{ONO}_{2}$ bond in a nitrate ester compound followed by hydrogen addition to form an alcohol group followed by either $[\mathrm{Cl}]^{-}$or $\left[\mathrm{NO}_{3}\right]^{-}$attachment. [47] The $\left[\mathrm{NG}+\mathrm{Cl}_{2}\right]^{-}$and $\left[\mathrm{PETN}+\mathrm{Cl}_{2}\right]^{-}$minor ions are formed via an ion-molecule attachment reaction between a nitrate ester compound and a $\left[\mathrm{Cl}_{2}\right]^{-}$ reactant ion (scheme vii).

The major product ion for the nitro-organic explosive taggant $\mathrm{DMNB}$ is $\left[\mathrm{NO}_{2}\right]^{-}$. The $\left[\mathrm{NO}_{2}\right]^{-}$fragment ion is generated by successive dissociation of the $\mathrm{C}-\mathrm{NO}_{2}$ bonds in the parent compound. [24]

\section{Nitrate Salt Ion Chemistry}

The product ions detected for $\mathrm{NH}_{4} \mathrm{NO}_{3}$ are $\left[\mathrm{NO}_{3}\right]^{-}$and $\left[\mathrm{HNO}_{3}+\mathrm{NO}_{3}\right]^{-}$. The $\left[\mathrm{HNO}_{3}+\mathrm{NO}_{3}\right]^{-}$product ion is likely formed via thermal decomposition of the salt during sample desorption to form gaseous ammonia and nitric acid $\left(\mathrm{HNO}_{3}\right)$. Following thermolysis, $\mathrm{HNO}_{3}$ undergoes an autoionization reaction with a $\left[\mathrm{NO}_{3}\right]^{-}$ fragment ion to yield a nitrate dimer complex bridged by an acidic hydrogen atom (scheme xi). [48-50] 
The $\left[\mathrm{NO}_{3}\right]^{-}$fragment ion may be produced from $\mathrm{HNO}_{3}$ by further thermal decomposition or proton transfer to a $[\mathrm{Cl}]^{-}$or $\left[\mathrm{Cl}_{2}\right]^{-}$reactant ion. The $\left[\mathrm{HNO}_{3}+\mathrm{NO}_{3}\right]^{-}$dimer assignment is supported by the strong response for $\left[\mathrm{NO}_{3}\right]^{-}$in its tandem mass spectrum.

\section{Organic Peroxide Ion Chemistry}

The nitrotoluene, nitroamine, nitrate ester, and nitrate salt explosives only produce ions with appreciable intensity in the negative ion detection mode. Conversely, the organic peroxide explosive HMTD produces appreciable ions in both the negative and positive ion detection modes. The ionization pathways for HMTD are dominated by thermal decomposition. For negative ion detection of HMTD, the major product ion is identified to be [HMTD- $\mathrm{NC}_{3} \mathrm{H}_{6} \mathrm{O}_{3}+\mathrm{H}+\mathrm{Cl}$ ] while the minor product ions are identified to be $\left[\mathrm{NC}_{2} \mathrm{H}_{2} \mathrm{O}_{2}\right]^{-}$, and $\left[\mathrm{NC}_{2} \mathrm{H}_{3} \mathrm{O}_{2}+\mathrm{Cl}\right]^{-}$. Possible structures and ionization pathways for the negative mode product ions are provided in scheme xii. Decomposition of the HMTD compound is likely initiated by thermal homolysis of all three O-O bonds to produce two $\left[\mathrm{NC}_{3} \mathrm{H}_{6} \mathrm{O}_{3}\right]$ fragments each with three oxygen radicals. $[9,27,51]$ The $\left[\mathrm{NC}_{3} \mathrm{H}_{6} \mathrm{O}_{3}\right]$ fragment may subsequently undergo either an attachment reaction or second order decomposition. In the attachment reaction scheme (pathway 1 in scheme xii), pairing of two oxygen radicals and hydrogen addition to the other oxygen radical in the $\left[\mathrm{NC}_{3} \mathrm{H}_{6} \mathrm{O}_{3}\right]$ fragment is followed by an ion-molecule attachment reaction with a $\left[\mathrm{CI}^{-}\right.$reactant ion to yield the [HMTD$\left.\mathrm{NC}_{3} \mathrm{H}_{6} \mathrm{O}_{3}+\mathrm{H}+\mathrm{Cl}\right]^{-}$major product ion. In the second order decomposition scheme (pathway 2 in scheme xii), a C-N bond in the $\left[\mathrm{NC}_{3} \mathrm{H}_{6} \mathrm{O}_{3}\right]$ fragment is cleaved to yield a $\left[\mathrm{NC}_{2} \mathrm{H}_{3} \mathrm{O}_{2}\right]$ fragment, which may undergo proton abstraction to form the $\left[\mathrm{NC}_{2} \mathrm{H}_{2} \mathrm{O}_{2}\right]^{-}$minor ion or $[\mathrm{Cl}]^{-}$attachment to form the $\left[\mathrm{NC}_{2} \mathrm{H}_{3} \mathrm{O}_{2}+\mathrm{Cl}\right]^{-}$minor ion. Formation of [HMTD- $\left.\mathrm{NC}_{3} \mathrm{H}_{6} \mathrm{O}_{3}+\mathrm{H}+\mathrm{Cl}\right]^{-},\left[\mathrm{NC}_{2} \mathrm{H}_{2} \mathrm{O}_{2}\right]^{-}$, and $\left[\mathrm{NC}_{2} \mathrm{H}_{3} \mathrm{O}_{2}+\mathrm{Cl}\right]^{-}$from the same $\left[\mathrm{NC}_{3} \mathrm{H}_{6} \mathrm{O}_{3}\right]$ fragment is supported by similar daughter ions being observed in the tandem mass spectra for the different product ions, including $[\mathrm{NCO}]^{-},\left[\mathrm{CO}_{2}\right]^{-}$, and $\left[\mathrm{NC}_{2} \mathrm{H}_{2} \mathrm{O}_{2}\right]^{-}$. Fragmentation of the $\mathrm{O}-\mathrm{O}$ bonds followed by fragmentation of a C-N bond is a favorable decomposition pathway for the HMTD compound due to the $\mathrm{O}-\mathrm{O}\left(\mathrm{D}_{\mathrm{E} O-\mathrm{O}}=145 \mathrm{~kJ} / \mathrm{mole}\right)$ and $\mathrm{N}-\mathrm{C}\left(\mathrm{D}_{\mathrm{E} O-\mathrm{O}}=308 \mathrm{~kJ} / \mathrm{mole}\right)$ bonds having the smallest bond dissociation energies in the molecule ( $D_{E}$ other $\left.\geq 348 \mathrm{~kJ} / \mathrm{mole}\right)$. [51]

For positive ion detection of HMTD, the major product ion is [HMTD- $\left.\mathrm{CH}_{2} \mathrm{O}-\mathrm{H}_{2} \mathrm{O}_{2}+\mathrm{H}\right]^{+}$while a minor product ion is $\left[\mathrm{NC}_{3} \mathrm{H}_{8} \mathrm{O}_{2}\right]^{+}$. Possible structures for the positive mode product ions are provided in scheme xiii. The $\left[\mathrm{HMTD}-\mathrm{CH}_{2} \mathrm{O}-\mathrm{H}_{2} \mathrm{O}_{2}+\mathrm{H}\right]^{+}$major product ion is likely formed via elimination of a formaldehyde and peroxide group respectively from a HMTD compound. [52-54] Specifically, the pathway may involve cleavage of a $\mathrm{O}-\mathrm{O}$ bond and $\mathrm{C}-\mathrm{N}$ bond to release a $\mathrm{CH}_{2} \mathrm{O}$ group followed by cleavage of two $\mathrm{C}-\mathrm{O}$ bonds and an reduction reaction to release a $\mathrm{H}_{2} \mathrm{O}_{2}$ group (scheme xiii). Second 
order decomposition of the $\left[\mathrm{HMTD}-\mathrm{CH}_{2} \mathrm{O}-\mathrm{H}_{2} \mathrm{O}_{2}+\mathrm{H}\right]^{+}$major product ion involving cleavage of a O-O bond is a possible source for the $\left[\mathrm{NC}_{3} \mathrm{H}_{8} \mathrm{O}_{2}\right]^{+}$minor ion. Decomposition of the [HMTD- $\left.\mathrm{CH}_{2} \mathrm{O}-\mathrm{H}_{2} \mathrm{O}_{2}+\mathrm{H}\right]^{+}$to form $\left[\mathrm{NC}_{3} \mathrm{H}_{8} \mathrm{O}_{2}\right]^{+}$is supported by the same daughter ions being observed in the tandem mass spectra for both product ions, including $\left[\mathrm{CH}_{2} \mathrm{NCH}_{2}\right]^{+}$and $\left[\mathrm{NC}_{2} \mathrm{H}_{3} \mathrm{O}_{2}\right]^{+}$.

To substantiate the empirical formulas assigned to the product ions for HMTD in the negative and positive ion detection modes, carbon 13 and nitrogen 15 labeled HMTD $\left({ }^{13} \mathrm{C}_{6} \mathrm{H}_{12} \mathrm{O}_{6}{ }^{15} \mathrm{~N}_{2}\right)$ was analyzed using the IMS/MS/MS instrument. The observed mass shifts in the mass spectra for the labeled HMTD were in agreement with the empirical formula assignments for the various product ions. For example, the mass spectra for the $\left[\mathrm{HMTD}-\mathrm{CH}_{2} \mathrm{O}-\mathrm{H}_{2} \mathrm{O}_{2}+\mathrm{H}\right]^{+}$product ion, which has empirical formula $\left[\mathrm{C}_{5} \mathrm{H}_{9} \mathrm{O}_{3} \mathrm{~N}_{2}\right]^{+}$, shifted from m/z 145 for non-labeled HMTD to m/z 152 for labeled HMTD, a mass shift which is consistent with a product ion containing 5 carbon atoms and 2 nitrogen atoms, therefore supporting the $\left[\mathrm{C}_{5} \mathrm{H}_{9} \mathrm{O}_{3} \mathrm{~N}_{2}\right]^{+}$assignment.

In contrast to the other explosives studied, the ionization pathways for TATP are more complex and take place primarily in the positive ion detection mode. The ionization pathways include thermal decomposition, methyl radical attack, and amine substitution from the isobutyramide reagent gas. A detailed description of the gas phase ion chemistry for TATP in the positive ion detection mode is provided elsewhere. [3] The major product ion for TATP in the positive ion detection mode is determined to have a $\mathrm{m} / \mathrm{z}$ of 89 and an empirical formula of $\left[\mathrm{C}_{4} \mathrm{H}_{9} \mathrm{O}_{2}\right]^{+}$. The empirical formula was derived by acquiring mass spectra for non-labeled TATP $\left(\mathrm{C}_{9} \mathrm{H}_{18} \mathrm{O}_{6}\right)$, deuterium labeled TATP $\left(\mathrm{C}_{9} \mathrm{D}_{18} \mathrm{O}_{6}\right)$, and carbon 13 labeled TATP $\left(\mathrm{C}_{6}{ }^{13} \mathrm{C}_{3} \mathrm{H}_{18} \mathrm{O}_{6}\right.$ where only the ring carbon atoms are labeled) using the IMS/MS/MS instrument. The mass spectra showed that the product ion mass shifted from $\mathrm{m} / \mathrm{z} 89$ for non-labeled TATP to $\mathrm{m} / \mathrm{z} 98$ for deuterium labeled TATP and to $\mathrm{m} / \mathrm{z} 90$ for carbon 13 labeled TATP, indicating that the product ion contains 9 hydrogen atoms from methyl groups in the TATP molecule, 1 carbon atom from the TATP ring, and by process of elimination 2 oxygen atoms likely from the TATP ring, yielding the empirical formula $\left[\mathrm{C}_{4} \mathrm{H}_{9} \mathrm{O}_{2}\right]^{+}$. Amine substitution from the reagent gas was eliminated as a possible ionization pathway for the $\left[\mathrm{C}_{4} \mathrm{H}_{9} \mathrm{O}_{2}\right]^{+}$product ion by analyzing TATP with nitrogen 15 labeled ammonia $\left({ }^{15} \mathrm{NH}_{3}\right)$ reagent in place of the isobutyramide reagent. The corresponding experiment did not show a mass shift for the product ion at $\mathrm{m} / \mathrm{z} 89$, indicating that the product ion did not contain an amine group from a nucleophilic substitution reaction with the reagent chemical. Partial structural information for the $\left[\mathrm{C}_{4} \mathrm{H}_{9} \mathrm{O}_{2}\right]^{+}$product ion was inferred by acquiring tandem mass spectra for the product ions at $\mathrm{m} / \mathrm{z}$ 89, 98, and 90 for the non-labeled TATP, deuterium labeled TATP, and carbon 13 labeled TATP samples, respectively. The tandem mass spectra showed that the daughter ion mass shifted from 
$\mathrm{m} / \mathrm{z} 43$ for non-labeled TATP to $\mathrm{m} / \mathrm{z} 46$ for deuterium labeled TATP and to $\mathrm{m} / \mathrm{z} 44$ for carbon 13 labeled TATP, indicating that the daughter ion contains 3 hydrogen atoms from a methyl group in the TATP molecule and 1 carbon atom and 1 oxygen atom from the TATP ring, suggesting a $\left[\left(\mathrm{CH}_{3}\right) \mathrm{CO}\right]$ substructure within the $\left[\mathrm{C}_{4} \mathrm{H}_{9} \mathrm{O}_{2}\right]^{+}$product ion. A structure and ionization pathway for the $\left[\mathrm{C}_{4} \mathrm{H}_{9} \mathrm{O}_{2}\right]^{+}$product ion is proposed in scheme xiv. Briefly, the proposed pathway involves decomposition of a TATP compound initiated by thermal homolysis of an $\mathrm{O}-\mathrm{O}$ bond to produce oxygen gas, acetone, and a carbonyloxide diradical intermediate. [26, 55] Following thermolysis, methyl radical attack and oxidation of a carbonyloxide intermediate yields a product ion with a molecular structure of $\left[\left(\mathrm{CH}_{3}\right)_{3} \mathrm{CO}_{2}\right]^{+}$. [56, 57] The methyl radical is presumably generated during the thermal decomposition of a TATP compound. [26, 52] A minor product ion with $\mathrm{m} / \mathrm{z} 73$ is observed for TATP in the positive ion detection mode. The empirical formula for the minor ion with $\mathrm{m} / \mathrm{z} 73$ is identified to be $\left[\mathrm{C}_{4} \mathrm{H}_{9} \mathrm{NH}_{2}\right]^{+}$using isotopic labeling. Specifically, the product ion mass shifted from $\mathrm{m} / \mathrm{z} 73$ for unlabeled TATP to $\mathrm{m} / \mathrm{z} 82$ for deuterium labeled TATP and to $\mathrm{m} / \mathrm{z} 74$ for carbon 13 labeled TATP. Analysis of TATP with nitrogen 15 labeled ammonia reagent resulted in a product ion mass shift from $\mathrm{m} / \mathrm{z} 73$ to $\mathrm{m} / \mathrm{z} 74$. Hence, the product ion contains 9 hydrogen atoms from methyl groups in the TATP molecule, 1 carbon atom from the TATP ring, and 1 nitrogen atom from a nucleophilic substitution reaction with the reagent chemical, leading to a proposed molecular structure of $\left[\left(\mathrm{CH}_{3}\right)_{3} \mathrm{CNH}_{2}\right]^{+}$.

A product ion with a $\mathrm{m} / \mathrm{z}$ value of 143 and 145 was observed for TATP in the negative ion detection mode. The product ion was only observed for unpurified TATP samples. The product ion for the unpure TATP was determined by isotopic labeling to be 2,2-dihydroperoxy propane $\left(\mathrm{C}_{3} \mathrm{H}_{8} \mathrm{O}_{4}\right)$ adducted with a $[\mathrm{Cl}]^{-}$reactant ion, and therefore, to have the molecular formula $\left[\mathrm{C}_{3} \mathrm{H}_{8} \mathrm{O}_{4}+\mathrm{Cl}\right]^{-}$. [58] The source of the dihydroperoxy propane contaminant in the TATP sample for the formation of the $\left[\mathrm{C}_{3} \mathrm{H}_{8} \mathrm{O}_{4}+\mathrm{Cl}\right]^{-}$product ion is presumed to be a contaminant or side-product formed during the synthesis of TATP. A possible pathway for the formation of dihydroperoxy propane during the TATP synthesis procedure, which involves the addition of hydrogen peroxide to acetone in the presence of an acid catalyst, is provided in scheme xv. [59] The dihydroperoxy propane impurity can be removed from the TATP sample by washing in dichloromethane and recrystallizing in hot methanol.

\section{E. Ion Chemistry Comparison between IMS and ITMS Based Systems}

Although the IMS based ETD studied here (Smiths Detection Inc.) and the ITMS based ETD studied previously (Morpho Detection Inc.) are both designed to detect explosives, the instruments are 
operated using different temperatures, reagent gases, and ion gating schemes. [1, 2] Specific differences between the instruments include the reaction region temperature being maintained at $165^{\circ}$ $\mathrm{C}$ for both negative and positive ion detection in the ITMS system compared to $115^{\circ} \mathrm{C}$ for negative ion detection and $225^{\circ} \mathrm{C}$ for positive ion detection in the IMS system as well as the reagent gases being dichloromethane and ammonia in the ITMS system compared to hexachloroethane and isobutyramide in the IMS system. Note that the reagent gas concentrations in the ITMS and IMS instruments are roughly the same. An additional difference between the instruments involves the ITMS system employing an ion trap gating scheme wherein an electric field in the reaction region is used to accumulate and subsequently pulse the ions into the drift region, increasing ion residence time in the reaction region by 1-2 orders of magnitude compared to the ion shutter gating scheme employed in the IMS system.

Examining similarities and differences in the gas phase ion chemistry between the IMS and ITMS instruments relative to the different reaction environments may provide additional insight into the ionization pathways inherent to the respective systems. A comparison between the major and minor product ions detected for TNT, RDX, EDGN, NG, PETN, $\mathrm{NH}_{4} \mathrm{NO}_{3}, \mathrm{HMTD}$, and TATP using the IMS and ITMS systems is provided in Table 4. Omitted from the comparison are DMNB, DNT, and HMX in addition to HMTD in the positive ion detection mode and TATP in the negative ion detection mode due to the explosives and conditions not being studied using the ITMS system.

For negative ion detection, the same major and minor product ions are mostly detected using the IMS and ITMS instruments. Common major product ions include $[\mathrm{TNT}-\mathrm{H}]^{-}$for TNT, $[\mathrm{RDX}+\mathrm{Cl}]^{-}$and $\left[\mathrm{RDX}+\mathrm{NO}_{2}\right]^{-}$ for RDX, $\left[\mathrm{NO}_{3}\right]^{-}$for $\mathrm{EGDN},\left[\mathrm{NG}+\mathrm{NO}_{3}\right]^{-}$for $\mathrm{NG},\left[\mathrm{PETN}+\mathrm{NO}_{3}\right]^{-}$for PETN, $\left[\mathrm{HNO}_{3}+\mathrm{NO}_{3}\right]^{-}$for $\mathrm{NH}_{4} \mathrm{NO}_{3}$, and [HMTD- $\left.\mathrm{NC}_{3} \mathrm{H}_{6} \mathrm{O}_{3}+\mathrm{H}+\mathrm{Cl}\right]^{-}$for HMTD. Common minor product ions include [NG-NO$\left.{ }_{2}+\mathrm{H}+\mathrm{Cl}\right]^{-}$and [NG$\left.\mathrm{NO}_{2}+\mathrm{H}+\mathrm{NO}_{3}\right]^{-}$for $\mathrm{NG},\left[\mathrm{PETN}-\mathrm{NO}_{2}+\mathrm{H}+\mathrm{Cl}\right]^{-}$and $\left[\mathrm{PETN}-\mathrm{NO}_{2}+\mathrm{H}+\mathrm{NO}_{3}\right]^{-}$for PETN, and $\left[\mathrm{NC}_{2} \mathrm{H}_{2} \mathrm{O}_{2}\right]^{-}$and [ $\left.\mathrm{NC}_{2} \mathrm{H}_{2} \mathrm{O}_{2}+\mathrm{H}+\mathrm{Cl}\right]^{-}$for HMTD. Because the common major product ions are detected at high abundance in both the IMS and ITMS systems, it can be concluded that their formation is energetically favorable and their lifetime sufficiently long (at least $10 \mathrm{msec}$ ) over a range of temperatures (at least 115 to $165^{\circ} \mathrm{C}$ ), reagent gases (at least dichloromethane and hexachloroethane), and residence times (at least $0.1 \mathrm{msec}$ to $10 \mathrm{msec}$ ) in the reaction region. Hence, the major product ions exhibit the necessary chemical stability and reproducibility for reliable formation from their corresponding nitro and nitrate containing explosives. Moreover, because the major and minor product ions common to the IMS and ITMS systems are primarily formed via thermal decomposition and/or ion-molecule attachment, it can be concluded 
that these ionization pathways are largely responsible for the utility of the ETDs in the negative ion detection mode.

One of the few differences between the IMS and ITMS instruments in the negative ion detection mode involves the $[\mathrm{NG}+\mathrm{Cl}]^{-}$and $[\mathrm{PETN}+\mathrm{Cl}]^{-}$product ions being detected as major ions in the IMS system as opposed to minor ions in the ITMS system. Higher abundances for the $[\mathrm{NG}+\mathrm{Cl}]^{-}$and $[\mathrm{PETN}+\mathrm{Cl}]^{-}$adducts in the IMS system are attributed to the lower temperature in the reaction region $\left(115^{\circ} \mathrm{C}\right.$ versus $\left.165^{\circ} \mathrm{C}\right)$ and the larger number of chlorine atoms per reagent molecule $(6 \mathrm{Cl}$ atoms in hexachloroethane versus 2 $\mathrm{Cl}$ atoms in dichloromethane), resulting in a higher $[\mathrm{Cl}]^{-}$to $\left[\mathrm{NO}_{3}\right]^{-}$concentration in the IMS system, and therefore, less competition from $\left[\mathrm{NG}+\mathrm{NO}_{3}\right]^{-}$and $\left[\mathrm{PETN}+\mathrm{NO}_{3}\right]^{-}$adduct formation. Specifically, lower temperature in the IMS instrument decreases the propensity for the nitrate ester adducts to dissociate in the reaction region and subsequently yield $\left[\mathrm{NO}_{3}\right]^{-}$, a favorable decomposition product given $\mathrm{NO}_{3}$ has a higher electron affinity than most other neutrals present in the reaction region, including $\mathrm{NO}_{2}$ and $\mathrm{Cl}$. [60] At similar concentrations, a reagent gas with a larger number of chlorine atoms per reagent molecule generates a higher concentration of $\mathrm{Cl}^{-}$reactant ions in the reaction region. [7] Systematic variation of the temperatures and reagent gases in the IMS and ITMS systems supported the conclusion that higher abundances for $[\mathrm{NG}+\mathrm{Cl}]^{-}$and $[\mathrm{PETN}+\mathrm{Cl}]^{-}$in the IMS system are attributed to both decreased $\left[\mathrm{NO}_{3}\right]^{-}$production via less thermal decomposition and increased $[\mathrm{Cl}]^{-}$production via larger number of chlorine atoms per reagent molecule. An additional difference between the IMS and ITMS instruments in the negative ion detection mode involves the $\left[\mathrm{RDX}+\mathrm{Cl}_{2}\right]^{-},[\mathrm{RDX}+\mathrm{Cl}+\mathrm{RDX}]^{-},\left[\mathrm{NG}+\mathrm{Cl}_{2}\right]^{-}$, and $\left[\mathrm{PETN}+\mathrm{Cl}_{2}\right]^{-}$ minor product ions only being observed in the IMS system. The presence of the $\left[\mathrm{RDX}+\mathrm{Cl}_{2}\right]^{-},\left[\mathrm{NG}+\mathrm{Cl}_{2}\right]^{-}$, and $\left[\mathrm{PETN}+\mathrm{Cl}_{2}\right]^{-}$product ions in the IMS system is likely due to $\left[\mathrm{Cl}_{2}\right]^{-}$reactant ions being generated from hexachloroethane and not from dichloromethane. The presence of the $[\mathrm{RDX}+\mathrm{Cl}+\mathrm{RDX}]^{-}$product ion in the IMS system is due to lower temperature in the reaction region decreasing the propensity for the dimer complex to dissociate.

For positive ion detection, comparison between the IMS and ITMS instruments is limited to the ion chemistry for TATP. The major product ion for TATP is $\left[\left(\mathrm{CH}_{3}\right)_{3} \mathrm{CO}_{2}\right]^{+}$in the IMS instrument and $\left[\left(\mathrm{CH}_{3}\right)_{2} \mathrm{CNH}_{2}\right]^{+}$in the ITMS system. The $\left[\left(\mathrm{CH}_{3}\right)_{3} \mathrm{CO}_{2}\right]^{+}$product ion is also detected in the ITMS system, albeit, at minor intensity. Conversely, the $\left[\left(\mathrm{CH}_{3}\right)_{2} \mathrm{CNH}_{2}\right]^{+}$product ion is not detected in the IMS system. The $\left[\left(\mathrm{CH}_{3}\right)_{3} \mathrm{CO}_{2}\right]^{+}$product ion is likely formed via thermal decomposition combined with methyl radical attack, whereas, the $\left[\left(\mathrm{CH}_{3}\right)_{2} \mathrm{CNH}_{2}\right]^{+}$product ion is formed via nucleophilic substitution of an ammonia molecule. $[3,61]$ Accordingly, absence of the $\left[\left(\mathrm{CH}_{3}\right)_{2} \mathrm{CNH}_{2}\right]^{+}$product ion in the IMS instrument is 
attributed to ammonia not being used as the reagent gas. As expected, replacing the isobutyramide reagent gas with ammonia in the IMS system yielded $\left[\left(\mathrm{CH}_{3}\right)_{2} \mathrm{CNH}_{2}\right]^{+}$, however, $\left[\left(\mathrm{CH}_{3}\right)_{3} \mathrm{CO}_{2}\right]^{+}$was still the major product ion, being detected at abundances $\sim 10$ times greater than $\left[\left(\mathrm{CH}_{3}\right)_{2} \mathrm{CNH}_{2}\right]^{+}$. [3] Lowering the temperature in the IMS system from $220^{\circ} \mathrm{C}$ to $100^{\circ} \mathrm{C}$ with the ammonia reagent gas decreased the abundance for $\left[\left(\mathrm{CH}_{3}\right)_{3} \mathrm{CO}_{2}\right]^{+}$by a factor of $\sim 10$, with the abundance for $\left[\left(\mathrm{CH}_{3}\right)_{2} \mathrm{CNH}_{2}\right]^{+}$being unchanged and $\left[\mathrm{TATP}+\mathrm{NH}_{4}\right]^{+}$becoming the major product ion. [3] In the ITMS instrument, which is operated at $165^{\circ}$ C, $\left[\left(\mathrm{CH}_{3}\right)_{2} \mathrm{CNH}_{2}\right]^{+}$is was detected at abundances $\sim 5$ times greater than $\left[\left(\mathrm{CH}_{3}\right)_{3} \mathrm{CO}_{2}\right]^{+}$. [2] However, changing from trapping (residence time up to $10 \mathrm{msec}$ ) to non-trapping (residence times less than 0.1 msec) operation in the reaction region of the ITMS instrument resulted in the abundances for $\left[\left(\mathrm{CH}_{3}\right)_{2} \mathrm{CNH}_{2}\right]^{+}$and $\left[\left(\mathrm{CH}_{3}\right)_{3} \mathrm{CO}_{2}\right]^{+}$being the same (i.e. the abundance for $\left[\left(\mathrm{CH}_{3}\right)_{3} \mathrm{CO}_{2}\right]^{+}$increased relative to $\left.\left[\left(\mathrm{CH}_{3}\right)_{2} \mathrm{CNH}_{2}\right]^{+}\right)$. [2] Overall, formation of the $\left[\left(\mathrm{CH}_{3}\right)_{3} \mathrm{CO}_{2}\right]^{+}$product ion is favored at higher temperatures and shorter residence times in the reaction region while formation of the $\left[\left(\mathrm{CH}_{3}\right)_{2} \mathrm{CNH}_{2}\right]^{+}$product ion requires ammonia reagent gas and is favored at moderate temperatures and longer residence times in the reaction region.

\section{Conclusions}

Molecular formulas, structures, and ionization pathways for the ion species produced in an IMS based ETD from a suite of nitro-organic, nitrate salt, and organic-peroxide explosives have been proposed using product and daughter ion mass information obtained by tandem mass spectrometry in combination with targeted isotopic labeling experiments and knowledge about sample composition and reaction environment. The major product ions are identified as [DNT-H] $]^{-}$for DNT, [TNT-H] $]^{-}$for TNT, $[\mathrm{RDX}+\mathrm{Cl}]^{-}$and $\left[\mathrm{RDX}+\mathrm{NO}_{2}\right]^{-}$for $\mathrm{RDX},[\mathrm{HMX}+\mathrm{Cl}]^{-}$and $\left[\mathrm{HMX}+\mathrm{NO}_{2}\right]^{-}$for $\mathrm{HMX},\left[\mathrm{NO}_{3}\right]^{-}$for $\mathrm{EGDN},[\mathrm{NG}+\mathrm{Cl}]^{-}$and $\left[\mathrm{NG}+\mathrm{NO}_{3}\right]^{-}$for $\mathrm{NG},[\mathrm{PETN}+\mathrm{Cl}]^{-}$and $\left[\mathrm{PETN}+\mathrm{NO}_{3}\right]^{-}$for PETN, $\left[\mathrm{HNO}_{3}+\mathrm{NO}_{3}\right]^{-}$for $\mathrm{NH}_{4} \mathrm{NO}_{3},\left[\mathrm{NO}_{2}\right]^{-}$for DMNB, [HMTD- $\left.\mathrm{NC}_{3} \mathrm{H}_{6} \mathrm{O}_{3}+\mathrm{H}+\mathrm{Cl}\right]^{-}$and $\left[\mathrm{HMTD}+\mathrm{H}-\mathrm{CH}_{2} \mathrm{O}-\mathrm{H}_{2} \mathrm{O}_{2}\right]^{+}$for $\mathrm{HMTD}$, and $\left[\left(\mathrm{CH}_{3}\right)_{3} \mathrm{CO}_{2}\right]^{+}$for TATP. For negative ion detection, the product ions observed for the IMS based ETD are mostly consistent with the product ions reported for an ITMS based ETD studied in a previous publication, indicating that the product ions exhibit favorable energetics over a range of operating conditions. A difference between the ETDs involves $[\mathrm{NG}+\mathrm{Cl}]^{-}$and $[\mathrm{PETN}+\mathrm{Cl}]^{-}$product ions being detected as major ions in the IMS system compared to minor ions in the ITMS system, which is attributed to decreased $\left[\mathrm{NO}_{3}\right]^{-}$production via less thermal decomposition and increased $[\mathrm{Cl}]^{-}$production via higher chlorine atom concentration in the IMS system. A second difference between the ETDs involves the major product ion for TATP being $\left[\left(\mathrm{CH}_{3}\right)_{3} \mathrm{CO}_{2}\right]^{+}$for the IMS system and $\left[\left(\mathrm{CH}_{3}\right)_{2} \mathrm{CNH}_{2}\right]^{+}$for the ITMS system. The $\left[\left(\mathrm{CH}_{3}\right)_{3} \mathrm{CO}_{2}\right]^{+}$product ion is determined to be 
favored at higher temperatures and shorter residence times in the reaction region while the $\left[\left(\mathrm{CH}_{3}\right)_{2} \mathrm{CNH}_{2}\right]^{+}$product ion is determined to require ammonia reagent gas to be formed.

\section{Acknowledgments}

JK acknowledges Richard Lareau for insightful discussion. This research was supported in part by an appointment for JTP to the Transportation Security Laboratory Visiting Scientist Program administered by the Oak Ridge Institute for Science and Education (ORISE) through an interagency agreement between the U.S. Department of Energy (DOE) and the U.S. Department of Homeland Security. ORISE is managed by Oak Ridge Associated Universities (ORAU) under DOE contract number DE-AC05060R23100. The U.S. Department of Homeland Security, Science and Technology Directorate, Transportation Security Laboratory sponsored this work under an interagency agreement with ORISE, HSHQDC-06-X-00329.

\section{Table Captions}

Table 1: Operating parameters for the benchtop IMS based ETD and the IMS based ETD attached to the API 2000 triple quadrupole mass spectrometer.

Table 2: Summary of the molecular formulas, ion masses, daughter ion masses, and reduced mobility values for the product ions formed during the analysis of DMNB, DNT, TNT, RDX, HMX, EGDN, NG, PETN, $\mathrm{NH}_{4} \mathrm{NO}_{3}, \mathrm{HMTD}$, and TATP.

\section{Tables}

Table 1

\begin{tabular}{|c|c|c|c|c|}
\hline \multirow{2}{*}{$\begin{array}{l}\text { Polarity } \\
\text { Parameter }\end{array}$} & \multicolumn{2}{|c|}{ Negative Ion Mode } & \multicolumn{2}{|c|}{ Positive Ion Mode } \\
\hline & Value & Unit & Value & Unit \\
\hline \multicolumn{5}{|c|}{ Electric Field Strengths } \\
\hline drift region & 257 & $\mathrm{~V} / \mathrm{cm}$ & 228 & $\mathrm{~V} / \mathrm{cm}$ \\
\hline \multicolumn{5}{|c|}{ Timings } \\
\hline ion gate pulse width & 200 & $\mu \mathrm{sec}$ & 200 & $\mu \mathrm{sec}$ \\
\hline ion gate repetition period & 30 & msec & 30 & msec \\
\hline \multicolumn{5}{|c|}{ Pressures } \\
\hline reaction region/drift region & 760 & torr & 760 & torr \\
\hline \multicolumn{5}{|c|}{ Temperatures } \\
\hline Desorber & 205 & ${ }^{\circ} \mathrm{C}$ & 205 & ${ }^{\circ} \mathrm{C}$ \\
\hline
\end{tabular}




\section{2}

24

2

\section{RDX}

29 RDX

30 RDX

31 RDX

$32^{\text {RDX }}$

33 HMX

$34 \mathrm{HMX}$

$34 \mathrm{HMX}$

$35 \mathrm{HMX}$

36 EGDN,

$37 \mathrm{NG}$,

38 PETN,

$3.9 \mathrm{NH}_{4} \mathrm{NO}_{3}$

$40^{\mathrm{NG}}$

$41 \mathrm{NG}$

$42^{N G}$

\section{$43_{N G}$}

$44 \mathrm{NG}$

$4 \overline{5 P E T N}$

46 PETN

47 PETN $\left[\text { PETN-NO } 2+\mathrm{H}+\mathrm{NO}_{3}\right]^{-}-$minor ion

$48^{\text {PETN }}$

49

50 PETN

$\left[\mathrm{NG}-\mathrm{NO}_{2}+\mathrm{H}+\mathrm{NO}_{3}\right]^{-}$- minor ion

\begin{tabular}{|l|l|l|}
\hline Inlet & 240 & $\circ$ \\
\hline reaction region/drift region (housing) & 115 & $\circ$ \\
\hline reaction region/drift region (gas) & 111 & $\circ$ \\
\hline
\end{tabular}

${ }^{\circ} \mathrm{C}$

\begin{tabular}{|l|l|}
\hline 285 & ${ }^{\circ} \mathrm{C}$ \\
\hline 225 & ${ }^{\circ} \mathrm{C}$ \\
\hline 217 & ${ }^{\circ} \mathrm{C}$ \\
\hline
\end{tabular}

Gas Flows

\begin{tabular}{|c|c|c|c|c|}
\hline \multicolumn{5}{|c|}{ Gas Hlows } \\
\hline sample gas $^{a}$ & 250 & $\mathrm{cc} / \mathrm{min}$ & 250 & $\mathrm{cc} / \mathrm{min}$ \\
\hline drift gas ${ }^{a}$ & 300 & $\mathrm{cc} / \mathrm{min}$ & 300 & $\mathrm{cc} / \mathrm{min}$ \\
\hline \multicolumn{5}{|c|}{ Reagents and Calibrants } \\
\hline reagent chemical & \multicolumn{2}{|c|}{ hexachloroethane } & \multicolumn{2}{|c|}{ isobutyramide } \\
\hline internal calibrant & \multicolumn{2}{|c|}{ 4-nitrobenzonitrile } & \multicolumn{2}{|c|}{ isobutyramide } \\
\hline
\end{tabular}

${ }^{\mathrm{a}}$ Purified air (5-25 ppm water and 50-100 ppm carbon dioxide) was used for both the sample and drift gases.

Table 2

$5 \mathrm{H}^{1} \mathrm{NH}_{4} \mathrm{NO}_{3} \quad\left[\mathrm{HNO}_{3}+\mathrm{NO}_{3}\right]^{-}$- major ion

52 HMTD $\left[\mathrm{NC}_{2} \mathrm{H}_{2} \mathrm{O}_{2}\right]^{-}$- minor ion

53 HMTD $\quad\left[\mathrm{NC}_{2} \mathrm{H}_{2} \mathrm{O}_{2}+\mathrm{H}+\mathrm{Cl}\right]^{-}$- minor ion

54 HMTD [HMTD- $\left.\mathrm{NC}_{3} \mathrm{H}_{6} \mathrm{O}_{3}-\mathrm{H}+\mathrm{Cl}\right]$ - minor ion

55 HMTD $\quad\left[\mathrm{HMTD}-\mathrm{NC}_{3} \mathrm{H}_{6} \mathrm{O}_{3}+\mathrm{H}+\mathrm{Cl}\right]$ - major ion

56 HMTD

57 HMTD

58

59 TATP

60 unpure

6 TATP

$\left[\mathrm{NC}_{3} \mathrm{H}_{8} \mathrm{O}_{2}\right]^{+}-$minor ion

$\left[\mathrm{HMTD}+\mathrm{H}-\mathrm{CH}_{2} \mathrm{O}-\mathrm{H}_{2} \mathrm{O}_{2}\right]^{+}$- major ion

6 TATP

62 


\section{Figure Captions}

Figure 1: Mass spectra from the analysis of a $100 \mathrm{ng}$ DNT sample (a), a $100 \mathrm{ng}$ TNT sample (b), a $100 \mathrm{ng}$ RDX sample (c), a 100ng HMX sample (d), a $100 \mathrm{ng}$ NG sample (e), and a $100 \mathrm{ng}$ PETN sample (f) obtained using the IMS/MS/MS instrument in the negative ion detection mode.

Figure 2: Mass-selected mobility spectra from the analysis of a $100 \mathrm{ng}$ RDX sample (top) and a $100 \mathrm{ng}$ PETN sample (bottom) obtained using the IMS/MS/MS instrument in the negative ion detection mode. Mass-selected mobility spectra for RDX are [Cl] at m/z 35 (brown), $\left[\mathrm{Cl}_{2}\right]^{-}$at $\mathrm{m} / \mathrm{z} 70$ (red), $[\mathrm{RDX}+\mathrm{Cl}]^{-}$at $\mathrm{m} / \mathrm{z}$ 257 (black), [RDX+NO $]^{-}$at m/z 268 (green), and [RDX+Cl+RDXI] at m/z 479 (blue). Mass-selected mobility spectra for PETN are $[\mathrm{Cl}]^{-}$at $\mathrm{m} / \mathrm{z} 35$ (grey), $\left[\mathrm{NO}_{3}\right]^{-}$at $\mathrm{m} / \mathrm{z} 62$ (brown), $\left[\mathrm{Cl}_{2}\right]^{-}$at $\mathrm{m} / \mathrm{z} 70$ (red), [PETN-NO $\left.{ }_{2}+\mathrm{H}+\mathrm{Cl}\right]^{-}$at $\mathrm{m} / \mathrm{z} 306$ (gold), [PETN-H] $]^{-}$at $\mathrm{m} / \mathrm{z} 315$ (green), [PETN+Cl] at $\mathrm{m} / \mathrm{z} 351$ (blue), and $\left[\mathrm{PETN}+\mathrm{NO}_{3}\right]^{-}$at $\mathrm{m} / \mathrm{z} 378$ (black).

Figure 3: Mobility and mobility selected mass spectra from the analysis of a $1000 \mathrm{ng} \mathrm{NH}_{4} \mathrm{NO}_{3}$ sample (left), a $1000 \mathrm{ng}$ HMTD sample (middle), and a $1000 \mathrm{ng}$ TATP sample (right). Top plots are the mobility spectra acquired using a benchtop IMS instrument. Bottom plots are the mass spectra acquired using the IMS/MS/MS instrument in the selected mobility monitoring mode. Mass spectra were obtained for the peaks with $\mathrm{K}_{0}$ values of 2.05 and $2.40 \mathrm{~cm}^{2} \mathrm{~V}^{-1} \mathrm{Sec}^{-1}$ for $\mathrm{NH}_{4} \mathrm{NO}_{3}$, the peaks with $\mathrm{K}_{0}$ values of 1.74 and $2.12 \mathrm{~cm}^{2} \mathrm{~V}^{-1} \mathrm{sec}^{-1}$ for HMTD, and the peaks with $\mathrm{K}_{0}$ values of 2.17 and $2.30 \mathrm{~cm}^{2} \mathrm{~V}^{-1} \mathrm{sec}^{-1}$ for TATP. Spectra for $\mathrm{NH}_{4} \mathrm{NO}_{3}$ were obtained in the negative ion detection mode while spectra for HMTD and TATP were obtained in the positive ion detection mode.

Figure 4: Proposed structures and ionization schemes for the gas phase ion chemistry inherent to the IMS based ETD.

\section{Figures}




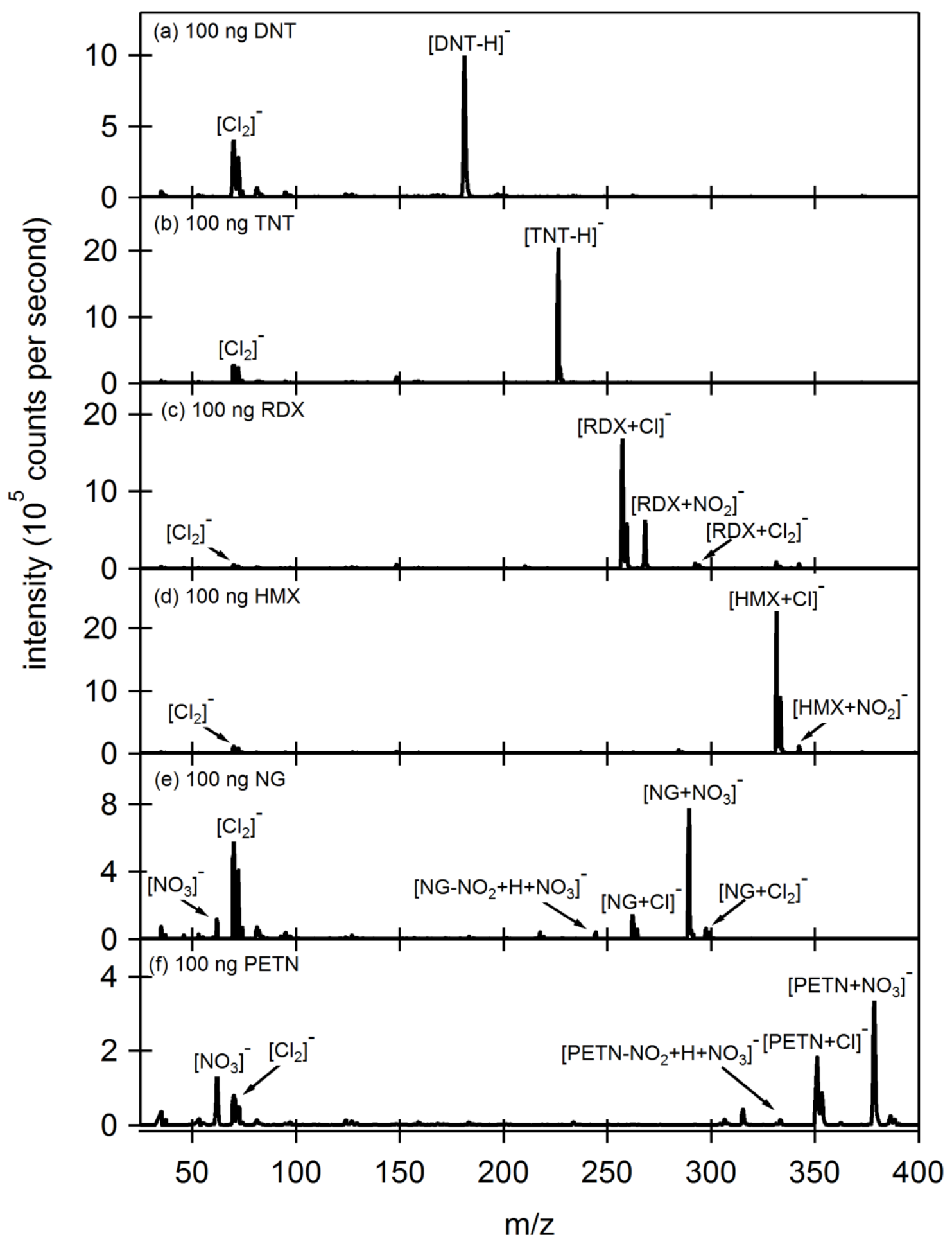

Figure 1 

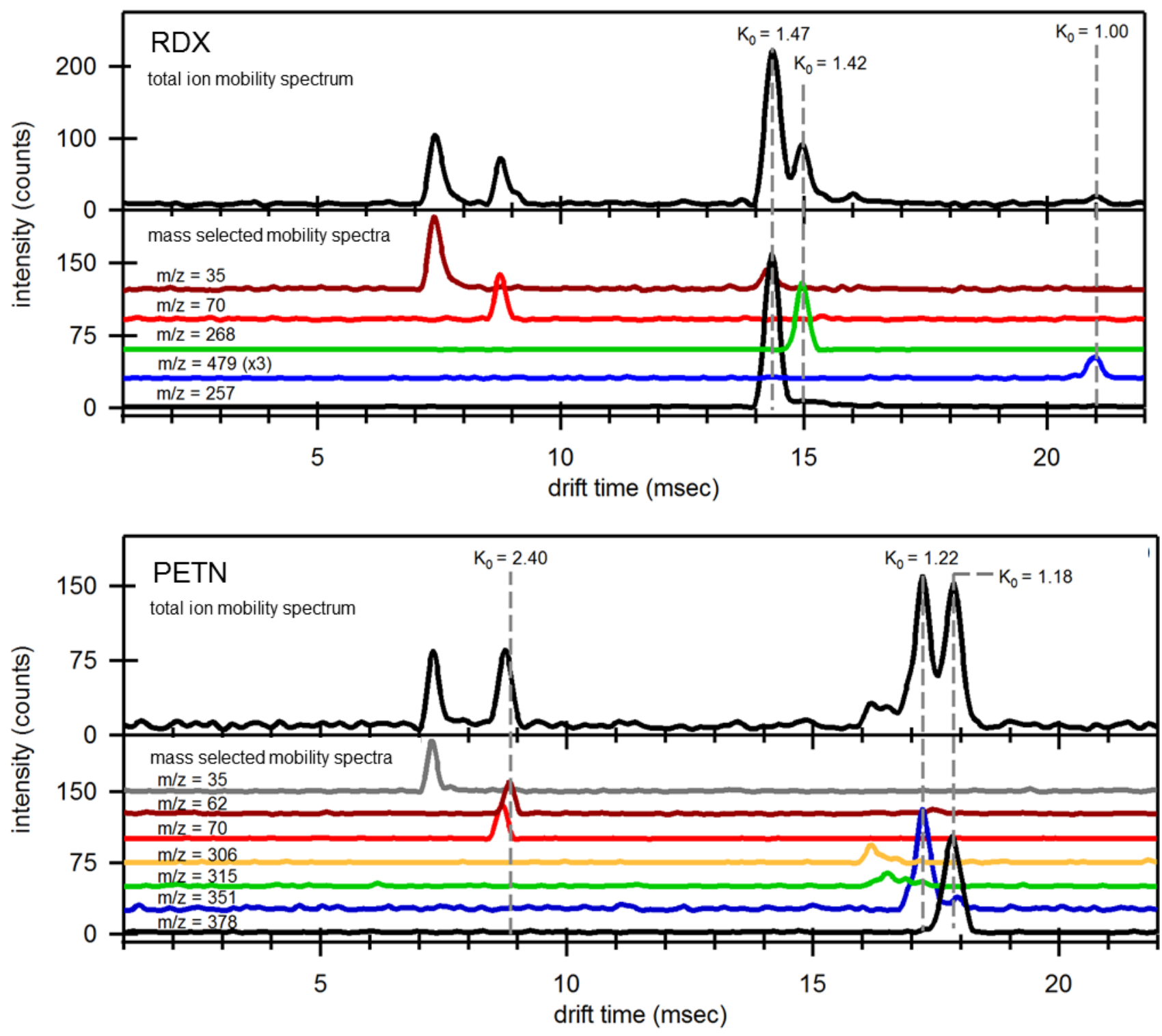

Figure 2 

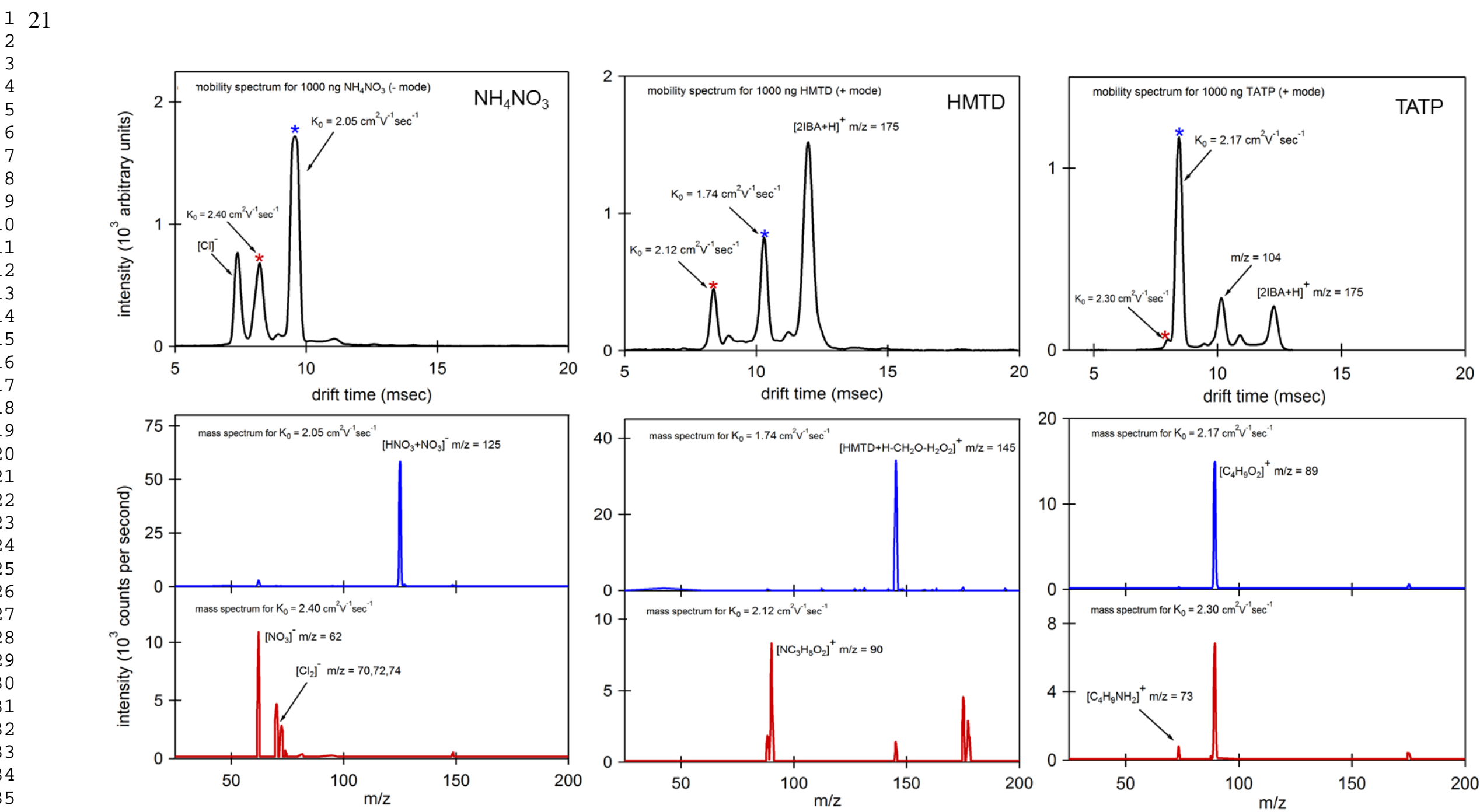

Figure 3 
(i) $\quad \mathrm{N}_{2}+\mathrm{e}^{-}$(high energy) $\rightarrow \mathrm{N}_{2}^{+}+\mathrm{e}^{-}$(low energy) $+\mathrm{e}^{-}$(high energy) $\mathrm{e}^{-}$(low energy) $+\mathrm{O}_{2} \rightarrow \mathrm{O}_{2}^{-}$

$\mathrm{O}_{2}^{-}+\mathrm{xH}_{2} \mathrm{O} \rightarrow \mathrm{O}_{2}^{-} \cdot \mathrm{xH}_{2} \mathrm{O}$ (where $1<\mathrm{x}<3$ )

$\mathrm{O}_{2}^{-} \cdot \mathrm{xH}_{2} \mathrm{O}+\mathrm{C}_{2} \mathrm{Cl}_{6} \rightarrow \mathrm{O}_{2}+\mathrm{Cl}_{\mathrm{n}}^{-} \cdot \mathrm{xH}_{2} \mathrm{O}+$ chlorocarbon fragments (where $\mathrm{n}=1$ or 2 )

(ii) $\quad \mathrm{N}_{2}+\mathrm{e}^{-}$(high energy) $\rightarrow \mathrm{N}_{2}^{+}+\mathrm{e}^{-}$(low energy) $+\mathrm{e}^{-}$(high energy)

$\mathrm{N}_{2}^{+}+2 \mathrm{~N}_{2} \rightarrow \mathrm{N}_{4}^{+}+\mathrm{N}_{2}$

$\mathrm{N}_{4}^{+}+\mathrm{H}_{2} \mathrm{O} \rightarrow \mathrm{H}_{2} \mathrm{O}^{+}+2 \mathrm{~N}_{2}$

$\mathrm{H}_{2} \mathrm{O}^{+}+(\mathrm{x}-1) \mathrm{H}_{2} \mathrm{O} \rightarrow \mathrm{H}^{+} \cdot \mathrm{xH}_{2} \mathrm{O}$ (where $\left.1<\mathrm{x}<3\right)$

$\mathrm{H}^{+} \cdot \mathrm{xH}_{2} \mathrm{O}+\mathrm{IBA}+\mathrm{IBA} \rightarrow 2 \mathrm{IBA} \cdot \mathrm{H}^{+} \cdot \mathrm{xH}_{2} \mathrm{O}$

(iii)

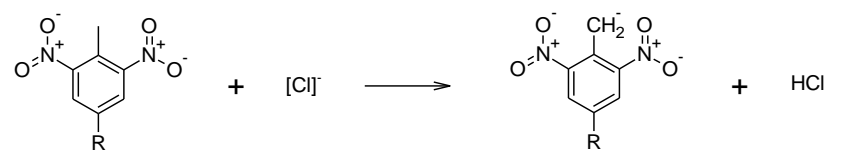

Where $\mathrm{R}=\mathrm{H}$ for DNT and $\mathrm{NO}_{2}$ for TNT

(iv)

$\longrightarrow+\left[\mathrm{Cl}_{2}\right]^{+}+\mathrm{e}_{\mathrm{R}}^{-} \longrightarrow \mathrm{HCl}_{+[\mathrm{Cl}}$

Where $\mathrm{R}=\mathrm{H}$ for DNT and $\mathrm{NO}_{2}$ for TNT

(v) $\quad \mathrm{M}+[\mathrm{Cl}]-\rightarrow[\mathrm{M}+\mathrm{Cl}]-($ where $\mathrm{M}$ is $\mathrm{RDX}$ or $\mathrm{HMX})$

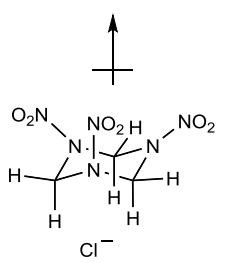

(vi) $\quad \mathrm{M}+$ heat $+\mathrm{e}^{-} \rightarrow\left[\mathrm{M}-\mathrm{NO}_{2}\right] \bullet+\left[\mathrm{NO}_{2}\right]^{-}$(where $\mathrm{M}$ is $\mathrm{RDX}$ or $\mathrm{HMX}$ )

$\mathrm{M}+\left[\mathrm{NO}_{2}\right]^{-} \rightarrow\left[\mathrm{M}+\mathrm{NO}_{2}\right]^{-}$

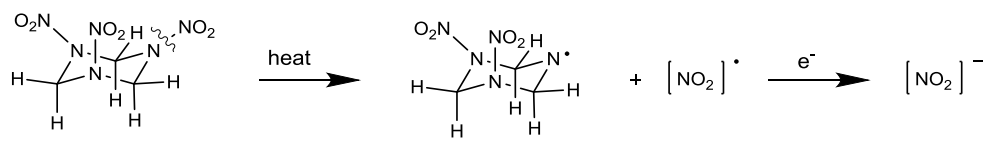

(vii) $\mathrm{M}+\left[\mathrm{Cl}_{2}\right]^{-} \rightarrow\left[\mathrm{M}+\mathrm{Cl}_{2}\right]^{-}$(where $\mathrm{M}$ is RDX, $\mathrm{HMX}, \mathrm{NG}$, or PETN)

(viii) $\mathrm{M}+[\mathrm{Cl}]^{-} \rightarrow[\mathrm{M}+\mathrm{Cl}]^{-}$(where $\mathrm{M}$ is RDX or HMX)

$\mathrm{M}+[\mathrm{M}+\mathrm{Cl}]^{-} \rightarrow[\mathrm{M}+\mathrm{Cl}+\mathrm{M}]^{-}$

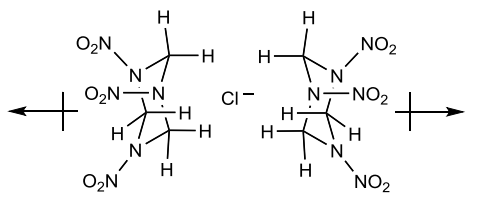

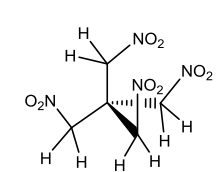

$\mathrm{Cl}^{-}$

(x) $\mathrm{M}+\left[\mathrm{NO}_{3}\right]^{-} \rightarrow\left[\mathrm{M}+\mathrm{NO}_{3}\right]^{-}$(where $\mathrm{M}$ is NG or PETN)

(xi) $\quad \mathrm{NH}_{4} \mathrm{NO}_{3}$ + heat $\rightarrow \mathrm{HNO}_{3}+\mathrm{NH}_{3}$

$\mathrm{HNO}_{3}+\left[\mathrm{NO}_{3}\right]^{-} \rightarrow\left[\mathrm{HNO}_{3}+\mathrm{NO}_{3}\right]^{-}$

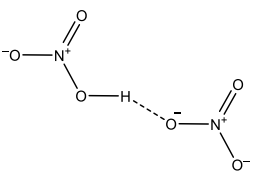

(xii)

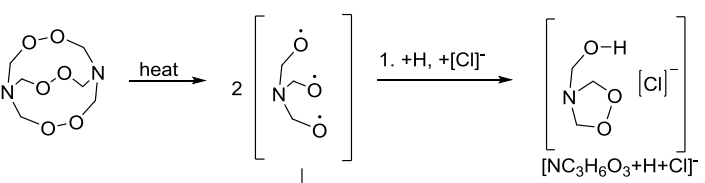

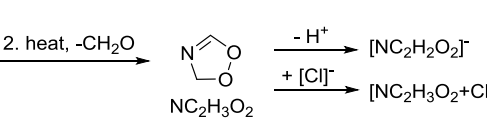

(xiii)

(xiv)

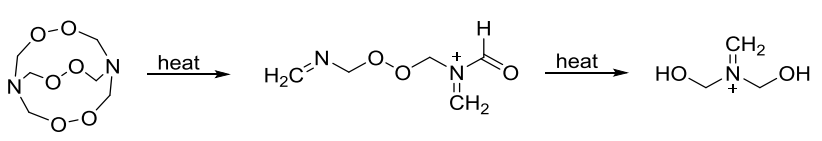

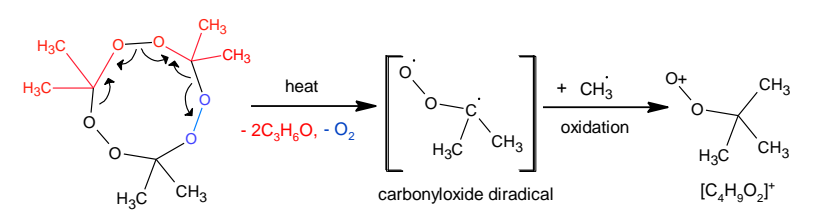

TATP

(xv)

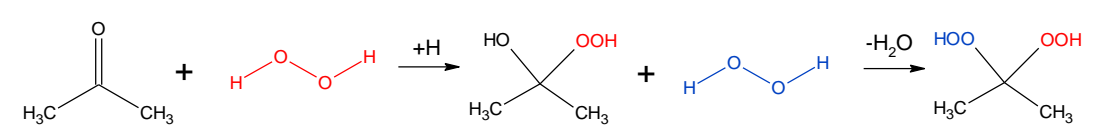

2,2 dihydroperoxy propan

\section{Figure 4}




\section{References}

[1] J. Kozole, J.R. Stairs, I. Cho, J.D. Harper, S.R. Lukow, R.T. Lareau, R. DeBono, F. Kuja, Analytical Chemistry, 83 (2011) 8596-8603.

[2] J. Kozole, J. Tomlinson-Phillips, J.R. Stairs, J.D. Harper, S.R. Lukow, R.T. Lareau, H. Boudries, H. Lai, C.S. Brauer, Talanta, 99 (2012) 799-810.

[3] J. Tomlinson-Phillips, A. Wooten, J. Kozole, J. Deline, P. Beresford, J. Stairs, Talanta, 127 (2014) 152162.

[4] G.A. Eiceman, Z. Karpas, Ion Mobility Spectrometry, 2nd ed., CRC Press Taylor \& Francis Group, Boca Raton, FL, 2005.

[5] C.J. Proctor, J.F.J. Todd, Analytical Chemistry, 56 (1984) 1794-1797.

[6] V. Bocos-Bintintan, A. Brittain, C.L.P. Thomas, The Analyst, 126 (2001) 1539-1544.

[7] K.A. Daum, D.A. Atkinson, R.G. Ewing, Talanta, 55 (2001) 491-500.

[8] K.A. Daum, D.A. Atkinson, R.G. Ewing, International Journal of Mass Spectrometry, 214 (2002) 257267.

[9] A.J. Marr, D.M. Groves, Proceedings for International Society for Ion Mobility Spectrometry, 6 (2003) 59-62.

[10] A. Jenkins; Ion Mobility Spectrometers, U.S Patent 5,200,614,, 1993.

[11] A. Jenkins, W.J. McGann; Ion Trap Mobility Spectrometer and Method of Operation for Enhanced Detection of Narcotics, U.S. Patent 5,491,337, 1996.

[12] D.J. Douglas, J.B. French, Journal of the American Society for Mass Spectrometry, 3 (1992) 398-408.

[13] D.D. Fetterolf, T.D. Clark, Journal of Forensic Sciences, 38 (1993) 28-39.

[14] A. Sysoev, A. Adamov, J. Viidanoja, R.A. Ketola, R. Kostiainen, T. Kotiaho, Rapid Communications in Mass Spectrometry, 18 (2004) 3131-3139.

[15] J. Kozole; Ion mobility spectrometer to mass spectrometer interface, U.S. Patent 8,536,518, 2013.

[16] B.H. Clowers, J. Herbert H. Hill, Analytical Chemistry, 77 (2005) 5877-5885.

[17] D. Collins, M. Lee, Anal Bioanal Chem, 372 (2002) 66-73.

[18] A.N. Krutchinsky, I.V. Chernushevich, V.L. Spicer, W. Ens, K.G. Standing, Journal of the American Society for Mass Spectrometry, 9 (1998) 569-579.

[19] K. Tang, A.A. Shvartsburg, H.-N. Lee, D.C. Prior, M.A. Buschbach, F. Li, A.V. Tolmachev, G.A. Anderson, R.D. Smith, Analytical Chemistry, 77 (2005) 3330-3339.

[20] G. Kaur-Atwal, G. O'Connor, A. Aksenov, V. Bocos-Bintintan, C. Paul Thomas, C. Creaser, International Journal for lon Mobility Spectrometry, 12 (2009) 1-14.

[21] L.L. Danylewych-May, Proceedings of the 1st International Symposium on Explosive Detection Technology, (1991) 672-686.

[22] A. Good, D.A. Durden, P. Kebarle, The Journal of Chemical Physics, 52 (1970) 212-221.

[23] I. Dzidic, D.I. Carroll, R.N. Stillwell, E.C. Horning, Analytical Chemistry, 48 (1976) 1763-1768.

[24] R.G. Ewing, D.A. Atkinson, G.A. Eiceman, G.J. Ewing, Talanta, 54 (2001) 515-529.

[25] G.A. Eiceman, D. Preston, G. Tiano, J. Rodriguez, J.E. Parmeter, Talanta, 45 (1997) 57-74.

[26] J.C. Oxley, J.L. Smith, H. Chen, Propellants, Explosives, Pyrotechnics, 27 (2002) 209-216.

[27] J.C. Oxley, J.L. Smith, H. Chen, E. Cioffi, Thermochimica Acta, 388 (2002) 215-225.

[28] G.E. Spangler, P.A. Lawless, Analytical Chemistry, 50 (1978) 884-892.

[29] M. Qasim, B. Moore, L. Taylor, L. Gorb, J. Leszczynski, P. Honea, International Journal of Molecular Sciences, 8 (2007) 1234-1264.

[30] J.D.D. Martin, J.W. Hepburn, The Journal of Chemical Physics, 109 (1998) 8139-8142.

[31] K.H. Bowen, G.W. Liesegang, B.S. Sanders, D.R. Herschbach, The Journal of Physical Chemistry, 87 (1983) 557-565.

[32] R. Cohen, Y. Zeiri, E. Wurzberg, R. Kosloff, The Journal of Physical Chemistry A, 111 (2007) 1107411083. 
[33] M. Tam, H.H. Hill, Analytical Chemistry, 76 (2004) 2741-2747.

[34] I. Cotte-Rodríguez, Z. Takáts, N. Talaty, H. Chen, R.G. Cooks, Analytical Chemistry, 77 (2005) 67556764.

[35] X. Zhao, J. Yinon, Journal of Chromatography A, 946 (2002) 125-132.

[36] M.E. Sigman, P.A. Armstrong, J.M. MacInnis, M.R. Williams, Analytical Chemistry, 77 (2005) 74347441.

[37] G.E. Spangler, J.P. Carrico, S.H. Kim, Proceedings for International Symposium on Analysis and Detection of Explosives, (1983) 267.

[38] A. Gapeev, M. Sigman, J. Yinon, Rapid Communications in Mass Spectrometry, 17 (2003) 943-948.

[39] D. Chakraborty, R.P. Muller, S. Dasgupta, I.W.A. Goddard, Journal of Computer-Aided Materials Design, 8 (2002) 203-212.

[40] M.H. Liu, G.F. Zheng, Journal of Theoretical and Computational Chemistry, 6 (2007) 341-351.

[41] R. Shaw, F.E. Walker, The Journal of Physical Chemistry, 81 (1977) 2572-2576.

[42] W.L. Ng, J.E. Field, H.M. Hauser, Journal of the Chemical Society, Perkin Transactions 2, (1976) 637639.

[43] M.A. Hiskey, K.R. Brower, J.C. Oxley, Journal of Physical Chemistry, 95 (1991) 3955-3960.

[44] A.C. Landerville, I.I. Oleynik, C.T. White, Shock Compression of Condensed Matter, (2009) 813-816.

[45] M. Li, G. Wang, X. Guo, Z. Wu, H. Song, Journal of Molecular Structure: THEOCHEM, 900 (2009) 9095.

[46] R.M.M.Y. Rajapakse, J.A. Stone, G.A. Eiceman, International Journal of Mass Spectrometry, 371 (2014) 28-35.

[47] D.M. Chambers, C.L. Brackett, O.D. Sparkman, Report from Lawrence Livermore National Laboratory, (2002).

[48] C. Oommen, S.R. Jain, Journal of Hazardous Materials, A67 (1999) 253-281.

[49] R. Gunawan, D. Zhang, Journal of Hazardous Materials, 165 (2009) 751-758.

[50] S. Cagnina, P. Rotureau, G. Fayet, C. Adamo, Physical Chemistry Chemical Physics, 15 (2013) 1084910858.

[51] S. Chang, H. Ko, S. Singamaneni, R. Gunawidjaja, V.V. Tsukruk, Analytical Chemistry, 81 (2009) 57405748.

[52] I. Cotte-Rodriguez, H. Hernandez-Soto, H. Chen, R.G. Cooks, Analytical Chemistry, 80 (2008) 15121519.

[53] A.J. Pena-Quevedo, S.P. Hernandez-Rivera, Proceedings of SPIE, (2009) 730303-730311.

[54] J.J. Brady, E.J. Judge, R.J. Levis, Rapid Communications in Mass Spectrometry, 24 (2010) 1659-1664.

[55] F. Dubnikova, R. Kosloff, J. Almog, Y. Zeiri, R. Boese, H. Itzhaky, A. Alt, E. Keinan, Journal of the American Chemical Society, 127 (2005) 1146-1159.

[56] W. Sander, Angew. Chem. Int. Ed. Engl., 29 (1990) 344-354.

[57] W.H. Bunnelle, Chem. Rev., 91 (1991) 335-362.

[58] I. Cho, T. Chamberlain, S. Brunk, R. Gill, D. LaMonica, Proceedings of the 3rd International Aviation Security Technology Symposium, (2001) 1-13.

[59] N.A. Milas, A. Golubovic, Journal of the American Chemical Society, 81 (1959) 6461-6462.

[60] M.J. Waltman, P. Dwivedi, H.H. Hill Jr, W.C. Blanchard, R.G. Ewing, Talanta, 77 (2008) 249-255.

[61] R.G. Ewing, M.J. Waltman, D.A. Atkinson, Analytical Chemistry, 83 (2011) 4838-4844. 
ETD based IMS/MS/MS
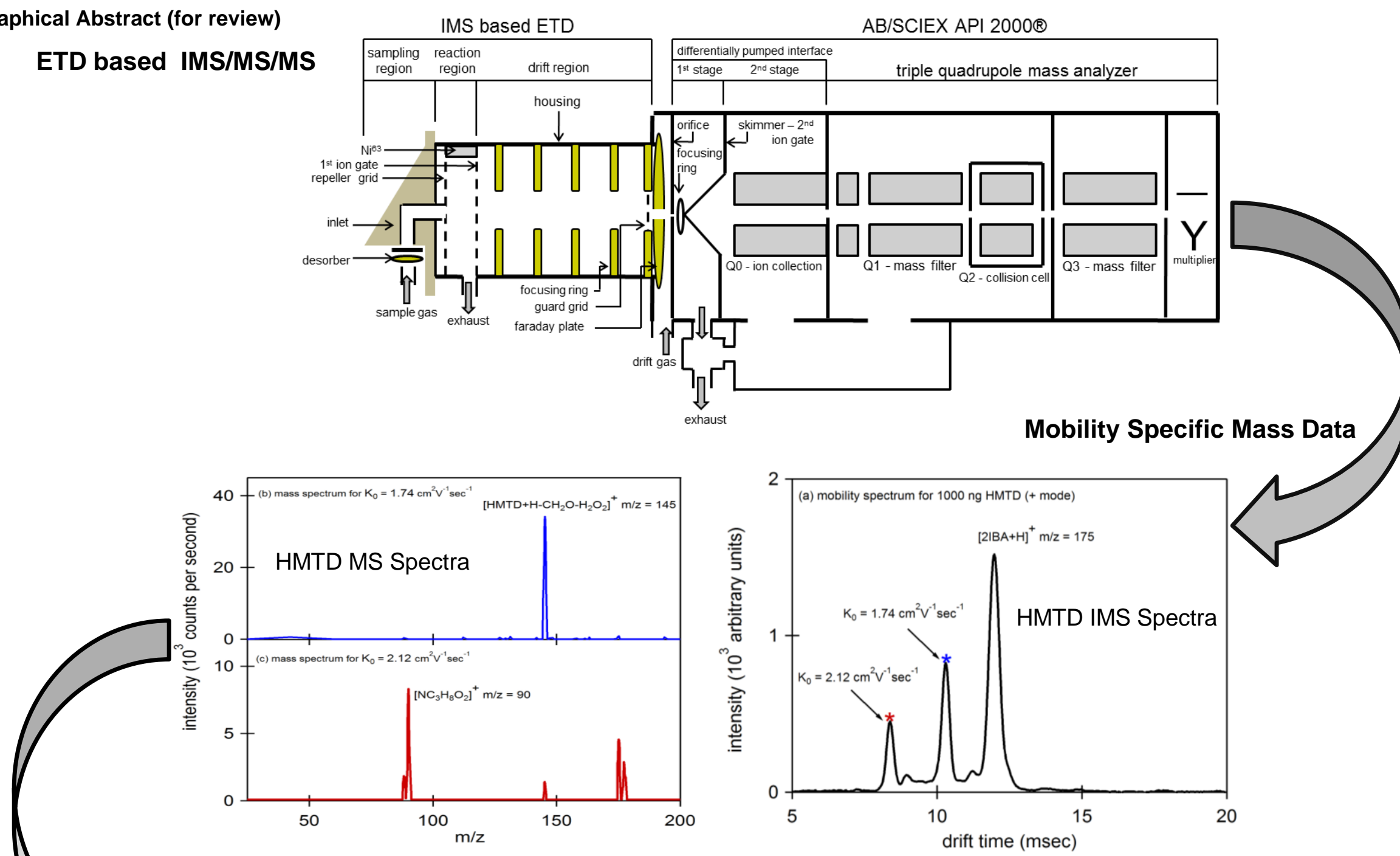

Structure and Ionization Pathway Information

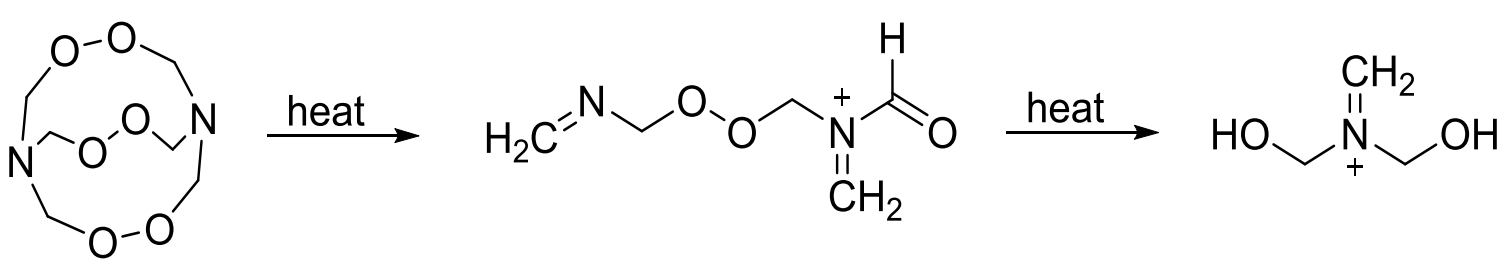

